\title{
Coupled Thermo-Hydro-Mechanical and Chemical Analysis of Expansive Clay Subjected to Heating and Hydration
}

\author{
L. DO N. GUIMARÃES, A. GENS and S. OLIVELLA* \\ UPC, Geotechnical Engineering and GeoSciences, Jordi Girona 1 and 3, Campus Nord, \\ Building D2, Barcelona 08034, Spain
}

(Received: 24 January 2005; in final form: 1 February 2006)

\begin{abstract}
A fully coupled formulation combining reactive transport and an existing thermo-hydro-mechanical (THM) code is presented. Special attention has been given to phenomena likely to be encountered in clay barriers used as part of containment systems of nuclear waste. The types of processes considered include hydrolysis, complex formation, oxidation/reduction reactions, acid/base reactions, precipitation/dissolution of minerals and cation exchange. Both kinetically-controlled and equilibrium-controlled reactions have been incorporated. The total analytical concentrations (including precipitated minerals) are adopted as basic transport variables and chemical equilibrium is achieved by minimizing Gibbs Free Energy. The formulation has been incorporated in a general purpose computer code capable of performing numerical analysis of engineering problems. A validation exercise concerning a laboratory experiment involving the heating and hydration of an expansive compacted clay is described.
\end{abstract}

Key words: coupled formulation, reactive transport, THM problem, swelling clays.

\section{Introduction}

Compacted swelling clays are often envisaged as a main component of engineered barriers for radioactive waste disposal. These barriers are subjected to thermal loading due to the heat emitted by the waste and to hydration from water coming from the adjacent rock. As a consequence of these thermo-hydraulic phenomena, mechanical and chemical changes arise that, in turn, may affect all other aspects of behaviour. A correct understanding and prediction of these barriers require, therefore, the performance of fully coupled thermo-hydro-mechanical and chemical (THMC) numerical analyses.

Indeed, in the development of numerical tools to analyze engineering problems involving geomaterials there has been a strong trend towards 
coupled formulations incorporating an increasing number of phenomena. The aim is to account for the full range of interactions between the various processes occurring simultaneously in the same problem. For instance fully coupled thermo-hydro-mechanical (THM) formulations have been put forward in the past by a number of researchers (e.g. Olivella et al., 1994; Gawin et al., 1995; Thomas and He, 1995).

On the geochemical field, reactive transport formulations initially developed for non-isothermal conditions and saturated porous media (e.g. Kirkner and Reeves, 1988; Friedly and Rubin, 1992; Saaltink et al., 1998) has been extended to non-isothermal conditions (e.g. Steefel and Lasaga, 1994) or unsaturated media (e.g. Yeh and Tripathi, 1991). At present, an

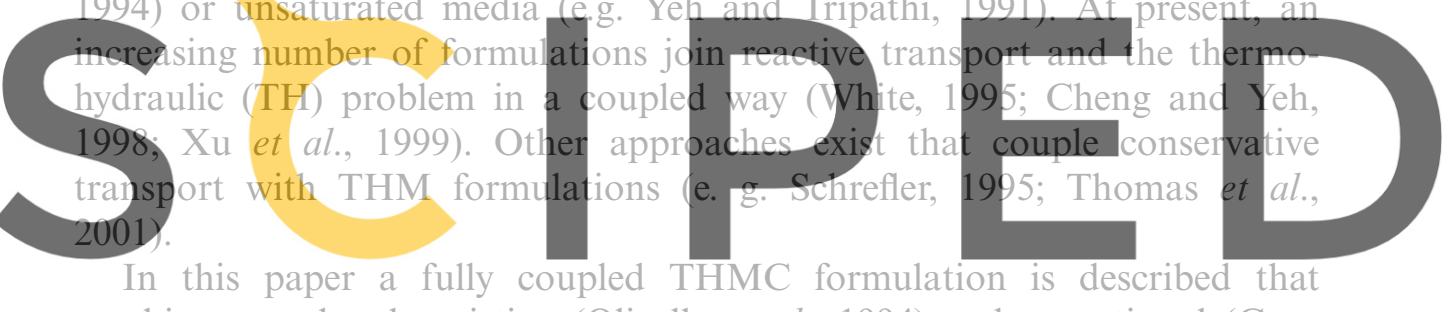

combines an already existing (Olivella et al., 1994) and operational (Gens

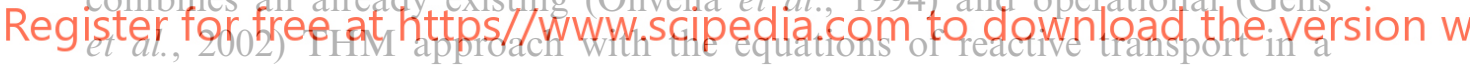

fully coupled manner. The formulation allows the performance of numer-

ical analyses considering all four aspects of behaviour: thermal, hydraulic, mechanical and chemical and their interactions. The formulation also takes into account the possibility that the material is partially saturated. Therefore, the term hydraulic should be interpreted in a general sense, i.e. including both liquid and gas flow phenomena.

A number of novel features are incorporated in the formulation. For instance the main unknowns of the transport equations are the total analytical concentrations (that includes precipitated minerals concentrations) instead of the more usual aqueous concentrations. Also, chemical equilibrium is solved by minimizing directly Gibbs free energy instead of resorting to the more generally used mass action law. Special attention is paid to the problems of dissolution/precipitation of minerals in local equilibrium. In this type of problems precipitated minerals may appear or disappear according to local conditions causing numerical difficulties that must be tackled in an efficient way. Although the formulation is general, particular consideration has been given to the phenomena (especially chemical phenomena) that are likely to occur in swelling clays used in an engineered barrier for nuclear waste isolation.

The formulation has been incorporated into a computer code and a number of issues concerning numerical implementation are discussed. Finally, the paper presents a validation exercise in which a highly compacted clay is subjected to simultaneous hydration and heating, mimicking in this way 
the actions likely to occur in an engineered barrier placed around high level nuclear waste.

\section{Mathematical Formulation of the Coupled THMC Problem}

\subsection{BASES OF THE FORMULATION}

The main aim of the paper is the development of a formulation for the reactive transport in an unsaturated deformable porous medium of several chemical species dissolved in the liquid phase but also present in the solid phase. Reactive transport refers to the movement through a porous

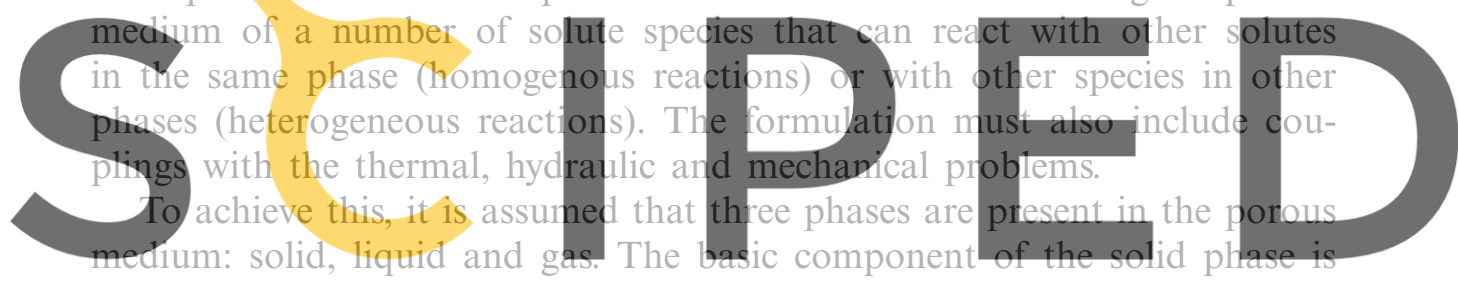

assumed not soluble but not inert as it can adsorb and exchange ions with

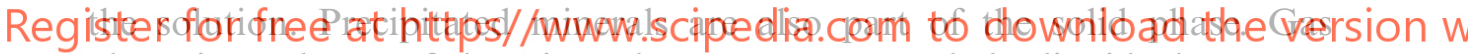

phase is made up of dry air and water vapour and the liquid phase contains water, solutes and dissolved air. Note that dry air is considered as a single species in spite of the fact that it is a mixture of gasses. Chemical reactions considered in the formulation include:

- Homogeneous reactions: aqueous complex formation, acid/base and oxidation/reduction.

- Heterogeneous reactions: dissolution/precipitation of minerals and cation exchange.

Local equilibrium is assumed for all the chemical reactions except for dissolution/precipitation of minerals where kinetics can also be considered. The use of one or the other of those two hypothesis must be based on the comparison between rates (or characteristic times) of concentration changes due to reactions and due to transport (Steefel and Lazaga 1994). Local equilibrium is the limiting case for kinetics when transport characteristic times are much higher then those of the chemical reaction. In addition, linear sorption and radioactive decay are also included in the formulation for specific analyses.

\subsection{THM FORMULATION}

Although the main focus of the paper is on the reactive transport problem, the THM formulation is briefly described for completeness. The approach used here is based on the THM formulation proposed in Olivella et al. 
(1994) and Olivella (1995) applied to clays (Gens et al., 1998, 2002). Using the compositional approach, the formulation is based on the establishment of balance equations for main mineral, water and air, instead of using phases. Thus, the contributions of phase changes automatically cancel.

As an example, the balance equation for the mass of water is expressed as

$$
\frac{\partial}{\partial t}\left(\phi S_{l} \rho_{l} w_{l}^{w}+\phi S_{g} \rho_{g} w_{g}^{w}\right)+\nabla \cdot\left(\mathbf{j}_{i}^{w}+\mathbf{j}_{g}^{w}\right)=f^{w}
$$

where $\phi$ is the porosity, $S_{l}$ and $S_{g}$ the liquid and gas degree of saturation, and $\rho_{g}$, the liquid and gas densities in $\mathrm{Kg} / \mathrm{m}^{3}$ of phase, $w^{w}$ the mass fractyon of water in the liquid (close to one in dilute solutions) and $v$ mass fraction of water vapour in the gas phase. The term $\phi S_{l} \rho_{l} w_{l}^{w}$ is the water content in the liquid phase per unit volume and $\phi S_{g} \rho_{g} w_{g}^{w}$ the water content in the gas phase. $\mathrm{j}_{l}^{w}$ and $\mathrm{j}_{g}^{w}$ are the mass flux of water in the liquid and gas phases, respectively. The term $f^{w}$ may represent, in the context of this paper, the water production or loss associated with precipitation or dissolution of minerals.

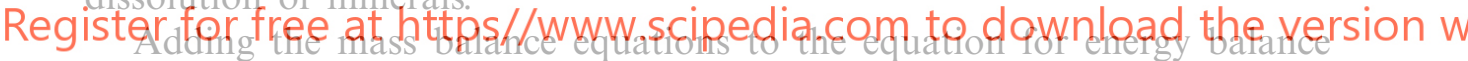

and momentum balance (equilibrium), the governing equations for the THMi problem are obtained. More details on the THMi formulation are given in Gens et al. $(1998,2002)$.

\subsection{TRANSPORT EQUATIONS}

The development of the reactive transport equations uses the general approach of Lichtner (1985), Kirkner and Reeves (1988) and Steefel and Lasaga (1994). Starting from the mass balance equation of each one of the species present in the medium, the final independent transport equations are obtained using the restrictions arising from the various reversible chemical reactions (local equilibrium assumption).

Let us consider the reactive transport of $N$ chemical species in a deformable unsaturated porous medium. The transport of every one of those species can be expressed as

$$
\frac{\partial}{\partial t}\left(\phi S_{l} \rho_{l} C_{i}\right)+\nabla \cdot \mathbf{j}_{i}=R_{i} \quad(i=1, \ldots, N)
$$

where $C_{i}$ is the concentration of species $i$ in moles $/ \mathrm{Kg}$ of solution and $R_{i}$ is the total production rate of species $i$ due to chemical reactions, in moles $/ \mathrm{m}^{3} / \mathrm{s}$. $\mathbf{j}_{i}$ is the total flux of species $i$ expresses moles $/ \mathrm{m}^{2} / \mathrm{s}$. As in Olivella et al. (1994), this flux is considered as the sum of advective and non-advective fluxes. Advective flux is, in turn, the sum of the movement of the liquid phase with respect to the solid phase (governed by the 
generalized Darcy's law) and of the solid phase with respect to the reference configuration. The non-advective flux is the product of molecular diffusion and mechanical dispersion. For simplicity, it is assumed that the mechanical dispersion tensor is the same for all the solutes. This has the advantageous consequence that electrical charge is conserved in the reactive transport equations when chemical reactions are charge balanced (Lichtner, 1985).

In order to make equation (2) valid for all species, including those in the solid phase, it is convenient to express the total flux $\mathbf{j}_{i}$ as

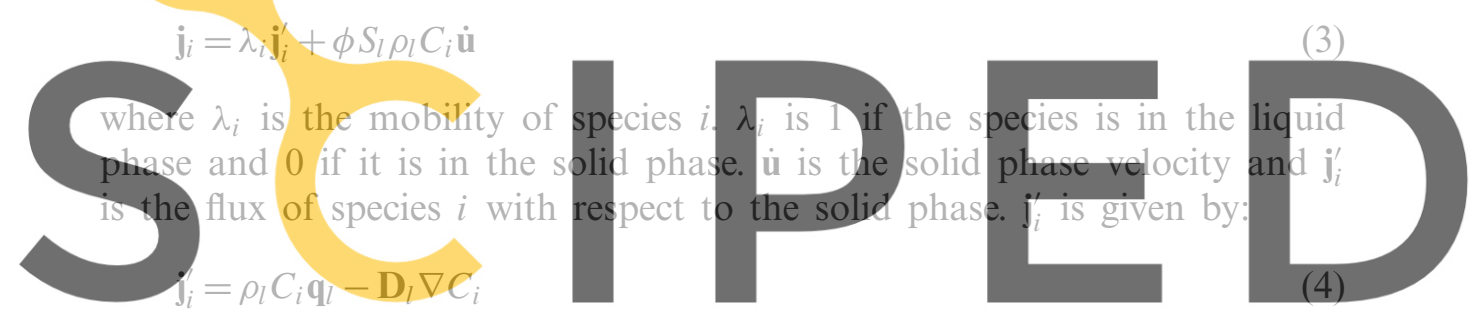

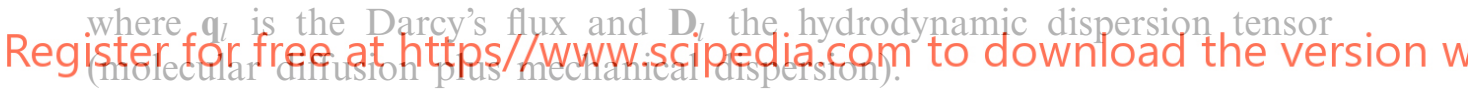

It is now necessary to introduce the reactions in local equilibrium to obtain the set of independent concentrations in the system. If $N_{x}$ is the number of reversible independent reactions in a system containing $N$ species, the number of independent chemical components is $N_{c}=N-N_{x}$ (full details are given in Reed, 1982; Lichtner, 1985; Kirkner and Reeves, 1988). It is now possible to classify the system in $N_{c}$ primary species and $N_{x}$ secondary species. Reversible reactions between the two types of species are expressed as (Steefel and Lasaga 1994):

$$
A_{i}=\sum_{j=1}^{N_{c}} v_{i j} A_{j} \quad\left(i=1, \ldots, N_{x}\right)
$$

where $A_{j}$ and $A_{i}$ are the chemical formulas of the primary and secondary species, respectively and $v_{i j}$ the number of moles of the primary species $j$ in a mol of the secondary species $i$. It should be noted that the classification of the species into primary and secondary ones is not unique (Lichtner, 1985).

The general notation for the chemical reactions used in (5) allows the incorporation of the most relevant geochemical processes (e.g. hydrolysis, complex formation, acid/base reactions, oxidation/reduction reactions, dissolution/precipitation of minerals) into the formulation. Cation exchange reactions can also be written in accordance with (5). Appelo and Postma (1993) introduce this latter type of reaction in the chemical equilibrium problem without algorithm modifications. 
Using the properties of reversible reactions (5), it is possible to derive the basic transport equation (details are given in Kirkner and Reeves, 1988; Steefel and Lasaga, 1994):

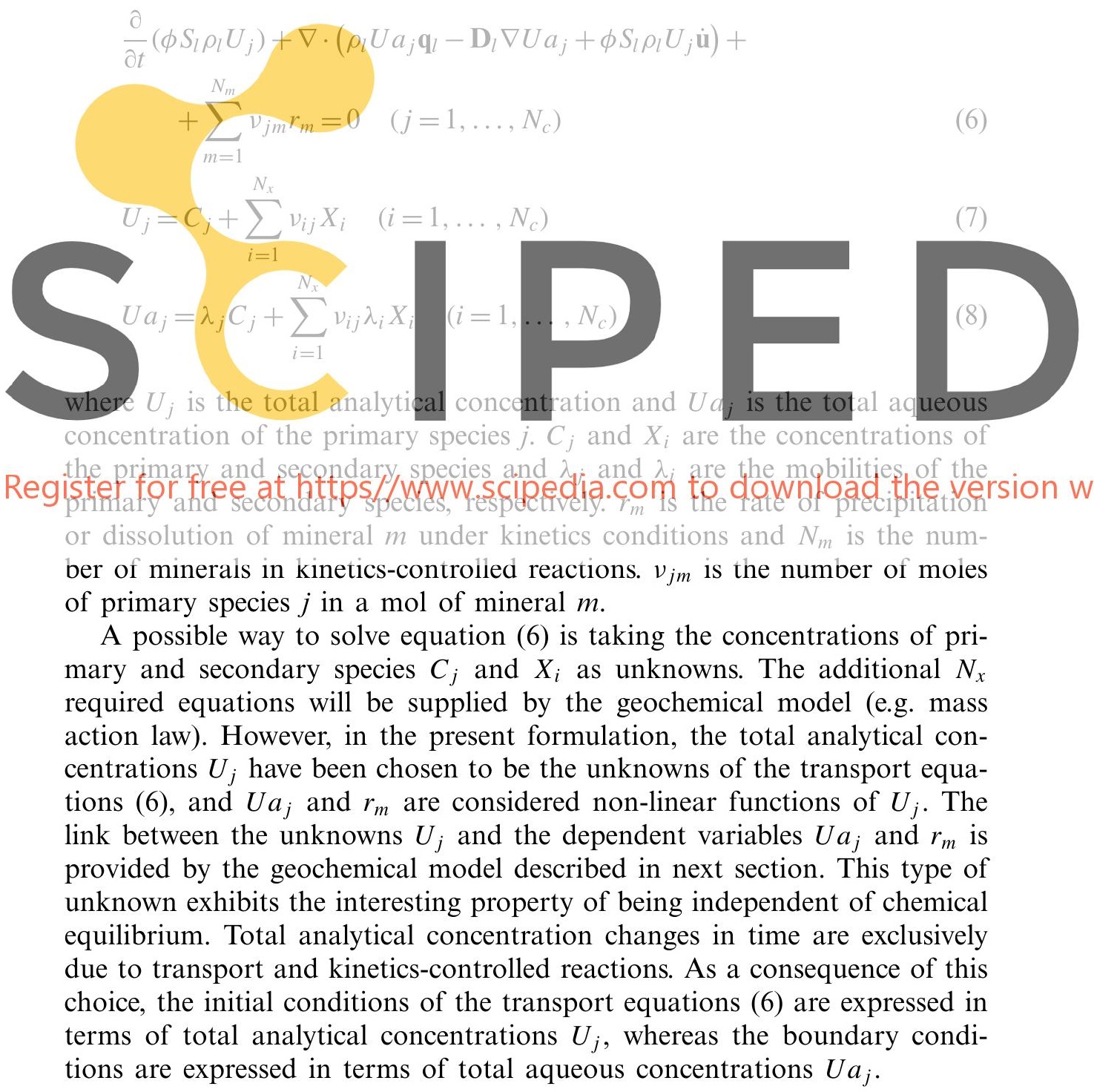

\subsection{CHEMICAL EQUILIBRIUM MODEL}

Most reactive transport formulations use the mass action law to solve the chemical equilibrium equations (e.g. Lichtner, 1985; Kirkner and Reeves, 1988; Steefel and Lasaga, 1994; Saaltink et al., 1998). In this formulation an alternative (though thermodynamically equivalent) approach is used, based 
on the minimization of Gibbs Free Energy. This approach has a wider application range extending to highly non-ideal brine systems (Harvie et al., 1987; Greenberg and Mфller, 1989). To compute the concentrations of the species in equilibrium, a Newton-Raphson algorithm is applied to the direct minimization of Gibbs Free Energy. Lagrange multipliers are used to incorporate the restrictions of the problem (Harvie et al., 1987).

\section{The minimization problem can be written as}
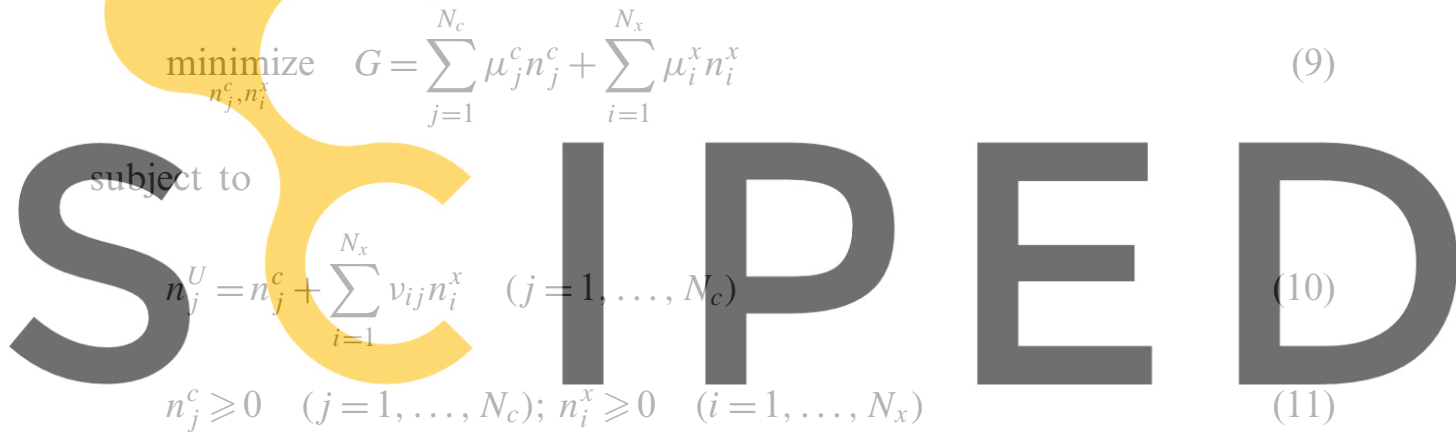

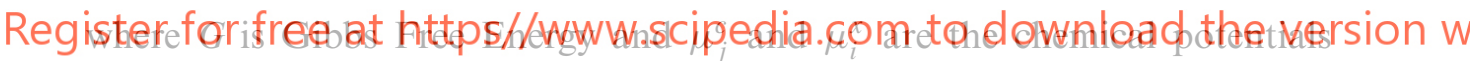

of the primary and secondary species. $n_{j}^{c}$ and $n_{i}^{x}$ are the number of moles of the primary and secondary species in a representative elementary volume (REV, as defined in Lichtner, 1985) are the variables to be optimized. $n_{j}^{U}$ is the total number of moles of a primary species $j$ in a REV. The number of moles $n_{j}^{c}, n_{i}^{x}$ and $n_{j}^{U}$ are directly related to concentrations $C_{j}, X_{i}$ and $U_{j}$, respectively.

Therefore, restriction (10) is the number-of-moles equivalent to equation (7). It is important to note that the main unknowns of the transport problem, $U_{j}$, can be considered constant in the chemical equilibrium problem. As pointed out before, when chemical reactions are charge balanced the reactive transport equations (6) conserve electrical charge. So, if the initial and boundary conditions of the transport problem are electrically neutral, then the restriction of electric neutrality of the chemical equilibrium problem is automatically satisfied.

The chemical potential of a species $k\left(\mu_{k}\right)$ is defined as (Anderson and Crerar, 1993):

$$
\mu_{k}=\left(\frac{\partial G}{\partial n_{k}}\right)_{P, T, \hat{n}_{k}}=\left(\mu_{k}\right)^{0}+R T \ln a_{k}
$$

Using (12), $\mu_{k}$ is obtained from $G$ once the pressure, temperature and number of moles of the other species in the system (represented by the symbol $\hat{n}_{k}$ ) are fixed. $\left(\mu_{k}\right)^{0}$ is the reference chemical potential that, by definition, depends only on pressure and temperature but not on the composition of the phase where species $k$ is located. The chemical activity of the species $k$, 
$a_{k}$, depends on the pressure, temperature and composition of the solution. It is usually given by a model based on thermodynamical theory and experimental observations. Therefore, the computation of the activity depends on the type of chemical system being considered. Pure minerals are a special case of a species with a chemical activity equal to 1 and, therefore, their chemical potentials depend only on pressure and temperature.

Equation (11) ensures that the species' concentration never become negative. It is possible to write these inequality restrictions using the following:

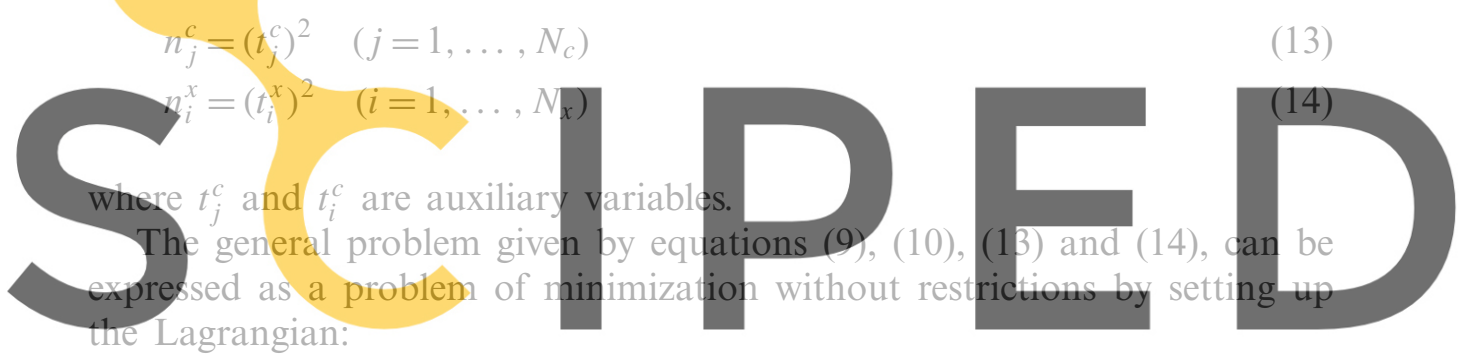

Register for free at https//www.scipedia.com to download the version w

$$
\begin{aligned}
L= & G+\sum_{j=1} \eta_{j}\left[n_{j}^{U}-n_{j}^{c}-\sum_{i=1} \nu_{i j} n_{i}^{x}\right]- \\
& -\sum_{j=1}^{N_{c}} \omega_{j}^{c}\left[n_{j}^{c}-\left(t_{j}^{c}\right)^{2}\right]-\sum_{i=1}^{N_{x}} \omega_{i}^{x}\left[n_{i}^{x}-\left(t_{i}^{x}\right)^{2}\right]
\end{aligned}
$$

where $\eta_{j}, \omega_{j}^{c}$ and $\omega_{i}^{x}$ are lagrangian multipliers corresponding to restrictions (10), (13) and (14), respectively.

The stationary points of the Lagrangian are:

$$
\begin{aligned}
& \frac{\partial L}{\partial n_{j}^{c}}=\mu_{j}^{c}-\eta_{j}-\omega_{j}^{c}=0 \quad\left(j=1, \ldots, N_{c}\right) \\
& \frac{\partial L}{\partial n_{i}^{x}}=\mu_{i}^{x}-\sum_{j=1}^{N_{c}} v_{i j} \eta_{j}-\omega_{i}^{x}=0 \quad\left(i=1, \ldots, N_{x}\right) \\
& \frac{\partial L}{\partial \eta_{j}}=n_{j}^{U}-n_{j}^{c}-\sum_{i=1}^{N_{x}} v_{i j} n_{i}^{x}=0 \quad\left(j=1, \ldots, N_{c}\right) \\
& \frac{\partial L}{\partial \omega_{j}^{c}}=n_{j}^{c}-\left(t_{j}^{c}\right)^{2}=0 \quad\left(j=1, \ldots, N_{c}\right) \\
& \frac{\partial L}{\partial \omega_{i}^{x}}=n_{i}^{x}-\left(t_{i}^{x}\right)^{2}=0 \quad\left(i=1, \ldots, N_{x}\right)
\end{aligned}
$$




$$
\begin{aligned}
& \frac{\partial L}{\partial t_{j}^{c}}=-2 \omega_{j}^{c} t_{j}^{c}=0 \quad\left(j=1, \ldots, N_{c}\right) \\
& \frac{\partial L}{\partial t_{i}^{x}}=-2 \omega_{i}^{x} t_{i}^{x}=0 \quad\left(i=1, \ldots, N_{x}\right)
\end{aligned}
$$

Equations (21) and (22) are the Kuhn-Tucker conditions for the primary and secondary species, respectively. This condition establishes that when the secondary species $i$ is present ( $t_{i}^{x}$ not equal to zero), its Lagrangian multi-

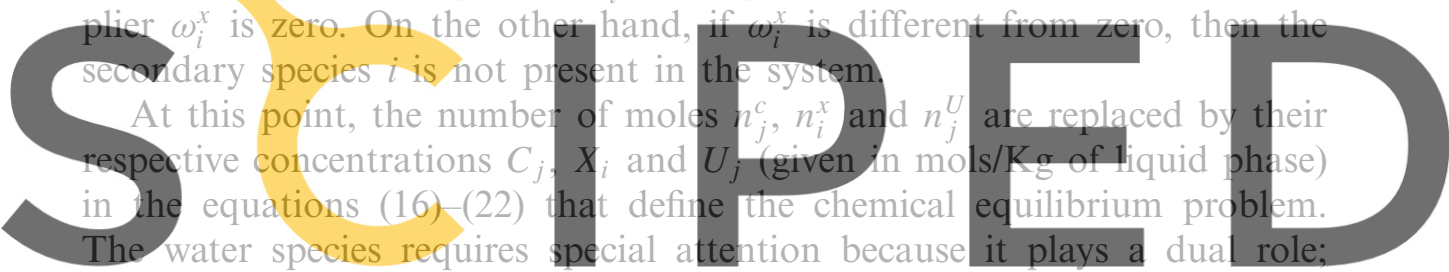

on the one hand it participates in the chemical reactions and, on the other

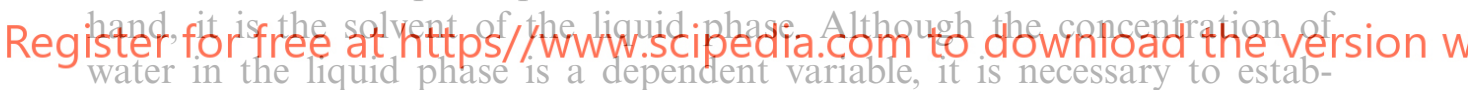

lish its mass balance (Reed, 1982) and its consideration may be important in brines or other concentrated solutions (Olivella et al., 1994). Moreover, if water participates in heterogeneous reactions such as dissolution and precipitation of minerals, it is also necessary to consider the source/sink term of water $f^{w}$ in equation (1). Since (1) already ensures the conservation of water mass, it is possible to eliminate its concentration $C_{1}$ (concentration of primary species 1) as an unknown of the chemical equilibrium problem together with the restrictions associated with this variable.

Another important simplification is to assume that all primary species will always be present in the medium. As a consequence of the Kuhn-Tucker condition (21), the lagrangian multipliers of the primary species $\omega_{j}^{c}$ are zero and, therefore, they can be eliminated together with equation (21). Thus, any mineral that may disappear from the porous medium must be considered as a secondary species. Moreover, according to equation (16), if $\omega_{j}^{c}=0$ then $\eta_{j}=\mu_{j}^{c}$. By substituting this result in (17), $\eta_{j}$ and equation (16) may be eliminated from the problem.

It is possible now to remove the auxiliary variables $t_{j}^{c}$ and $t_{i}^{x}$ from the problem and prescribe the restrictions (21) and (22) algorithmically (Harvie et al., 1987) by writing them again in (11) as inequality restrictions. In the (22) Kuhn-Tucker condition, it is possible to substitute the concentration $X_{i}$ for the auxiliary variable $t_{i}^{x}$. Now, concentration $X_{i}$ is an unknown of the problem together with $C_{j}$ and $\omega_{i}^{x}$.

Using the considerations above, the chemical equilibrium problem reduces to 


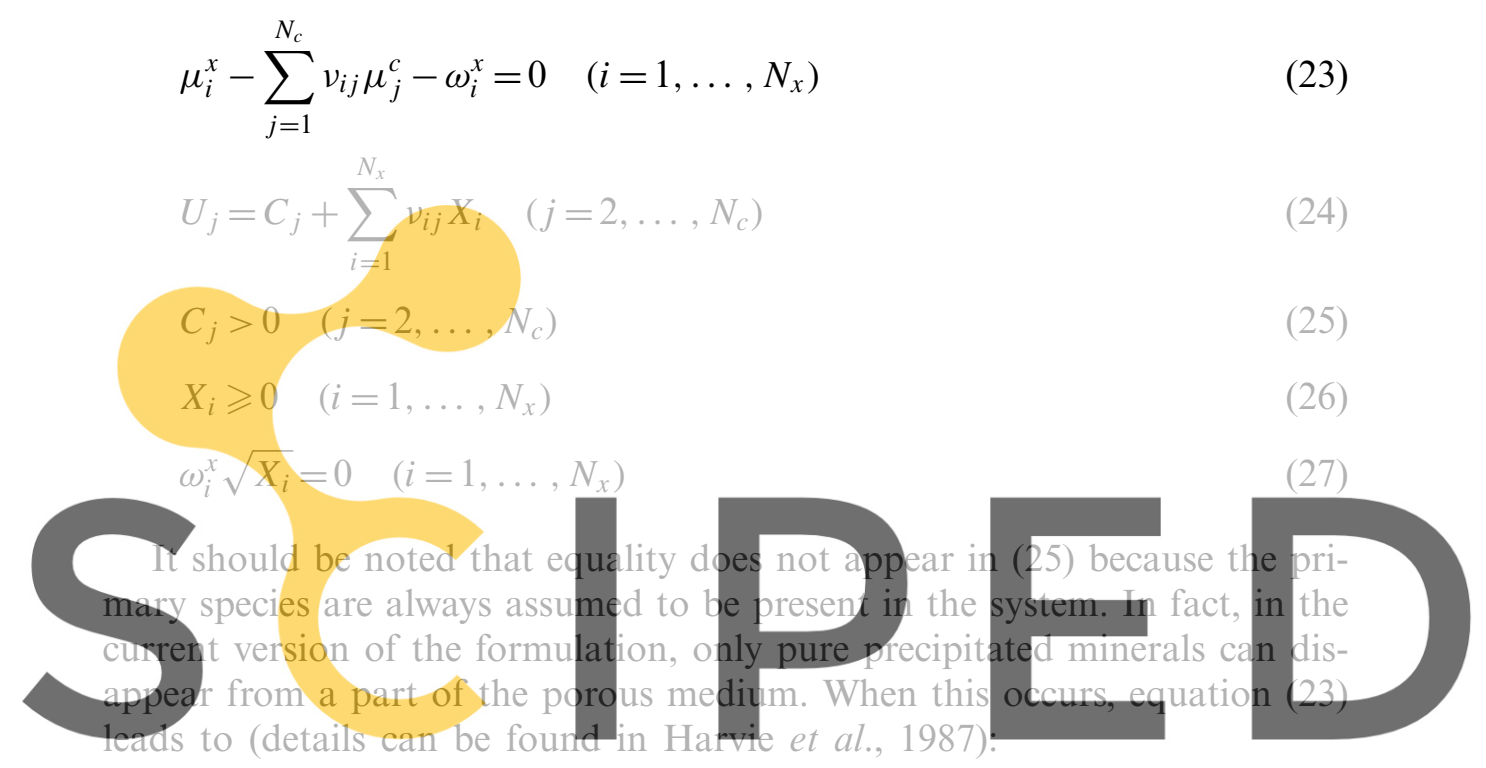

\section{Registerwor freelatsattps//www.scipedia.com to download the(zersion w}

where $\Omega_{i}$ is the saturation state of mineral $i$, given by

$$
\Omega_{i}=\frac{\prod_{j=1}^{N_{c}} a_{j}^{\nu_{i j}}}{K_{i}}
$$

using the fact that the activity of the pure mineral is $a_{i}=1 . a_{j}$ is the activity of the primary species and $K_{i}$ is the equilibrium constant of the reaction (solubility product). $K_{i}$ is given by

$$
\ln K_{i}=\frac{\left(\mu_{i}^{x}\right)^{0}}{R T}-\sum_{j=1}^{N_{c}} v_{i j} \frac{\left(\mu_{j}^{c}\right)^{0}}{R T}
$$

where $\left(\mu_{j}^{c}\right)^{0}$ and $\left(\mu_{i}^{x}\right)^{0}$ are the reference chemical potentials of the primary and secondary species, respectively.

When a mineral $i$ is present $\left(X_{i}>0\right)$, the solution will be saturated with respect to this mineral implying that $\Omega_{i}=1$ and $\omega_{i}^{x}=0$. The Kuhn-Tucker condition (27) is thus naturally satisfied.

A solution can never be supersaturated with respect of a mineral in local equilibrium, i.e. $\Omega_{i} \leqslant 1$. This indicates that it is necessary to add the physical restriction:

$$
\omega_{i}^{x} \geqslant 0
$$




\subsection{DEGREES OF FREEDOM RESULTING FROM THE FORMULATION}

An important feature of the formulation concerns the treatment of the dissolution/precipitation processes, especially in those cases where a particular mineral may disappear from part of the domain. In the formulations based on the mass action law the process must be specifically removed from the system of the equations in that part of the domain. Rubin (1983), Lichtner (1985) and Saaltink et al. (1998) discuss in some detail this moving boundary problem.

When the process is removed from the system of equations, the number of unknowns of the problem $\left(N_{u}\right)$ is consistent with the number of degrees of freedom $\left(N_{f}\right)$ computed according to the Gibbs' phase rule (Bethke, 1996; Steefel and MacQuarrie, 1996): $N_{u}=N_{f}=N_{c}-N_{\Phi}+2$, where $N_{c}$ is the number of primary species (as defined in this paper) and $N_{\Phi}$ is the number of phases of the system (liquid, minerals and gases in equilibrium with the solution). The two additional degrees of freedom correspond to temperature and pressure.

The formulation presented in this paper provides an alternative for solving the reactive transport problem as defined by the transport equation (6) and the chemical equilibrium equations (23)-(27) and (31). The unknowns of the transport equations (6) are now the concentrations of the total primary species, $U_{j}$, and the unknowns of the optimization scheme that defines the chemical equilibrium problem are the concentrations of the primary and secondary species, $C_{j}$ and $X_{i}$, respectively together with the Lagrangian multipliers for the precipitated minerals in local equilibrium, $\omega_{i}^{x}$.

An important characteristic of the algorithm described lies in restriction (26). When a mineral disappears in a particular zone of the domain, the restriction is simply activated. Using this algorithm, the number of degrees of freedom is constant and it does not depend on the presence or absence of the precipitated minerals in equilibrium, although the total number does not coincide now with the minimum degrees of freedom computed according to thermodynamic rules $\left(N_{u}=N_{c}+1>N_{f}\right)$. The constancy of the number of degrees of freedom throughout the domain is very advantageous from the point of view of numerical implementation. The formulation is therefore well adapted to problems with highly dynamic appearance/disappearance of minerals as in the validation exercise presented in Section 4.

\section{Numerical Implementation}

In this section, a number of features related to the numerical implementation of the reactive transport formulation presented earlier are described. The main objective is to use the Newton-Raphson method to solve the non-linear system of equations that results from the discretization of the 
transport equations. Those equations can be discretized by the Finite Element method using the procedures reported in Olivella et al. (1996). To apply the Newton-Raphson method, the following derivatives are required:

$$
\begin{aligned}
& \frac{\partial U a_{j}}{\partial U_{k}}=\lambda_{j} \frac{\partial C_{j}}{\partial U_{k}}+\sum_{i=1}^{N_{x}} v_{i j} \lambda_{i} \frac{\partial X_{i}}{\partial U_{k}} \quad\left(j=2, \ldots, N_{c}\right) \\
& \frac{\partial r_{m}\left(C_{j}, X_{i}\right)}{\partial U_{k}}=\sum_{j=2}^{N_{c}} \frac{\partial r_{m}}{\partial C_{j}} \frac{\partial C_{j}}{\partial U_{k}}+\sum_{i=1}^{N_{x}} \frac{\partial r_{m}}{\partial X_{i}} \frac{\partial X_{i}}{\partial U_{k}} \quad\left(m=1, \ldots, N_{m}\right)
\end{aligned}
$$

where $U_{k}$ is the total analytical concentration of the $k$ primary species. As the dependent variables $U a_{j}$ and $r_{m}$ are known functions of the primary and secondary species concentrations ( $C_{j}$ and $X_{i}$, respectively), what is in fact required is the following tangent matrix:

$$
\left(\frac{\partial C_{j}}{\partial U_{k}}, \frac{\partial X_{i}}{\partial U_{k}}\right) \quad \text { para }\left\{\begin{array}{l}
j=2, \ldots, N_{c} \\
i=1, \ldots, N_{x} \\
k=2, \ldots, N_{c}
\end{array}\right.
$$

that provides the derivatives of the concentrations of the primary and secondary species with respect to the total analytical concentrations of the primary species.

The tangent matrix in (33) is obtained differentiating the equations of the chemical equilibrium problem with respect to $U_{k}$. Once the chemical equilibrium problem is solved and the minerals in equilibrium with the solution are known, the following equations can be established:

a) For primary species:

Differentiating the local mass balance equations (using the definition of total analytical concentration):

$$
U_{j}=C_{j}+\sum_{i=1}^{N_{x}} v_{i j} X_{i} \Rightarrow \frac{\partial U_{j}}{\partial U_{k}}=\delta_{j k}=\frac{\partial C_{j}}{\partial U_{k}}+\sum_{i=1}^{N_{x}} v_{i j} \frac{\partial X_{i}}{\partial U_{k}}
$$

where $\delta_{j k}$ is Kronecker's delta:

$$
\delta_{j k}= \begin{cases}1 & \text { if } j=k \\ 0 & \text { if } j \neq k\end{cases}
$$

b) For secondary species:

Differentiating Kuhn-Tucker's condition (27):

$$
\omega_{i}^{x} \sqrt{X_{i}}=0 \Rightarrow \sqrt{X_{i}} \frac{\partial \omega_{i}^{x}}{\partial U_{k}}+\frac{\omega_{i}^{x}}{2 \sqrt{X_{i}}} \frac{\partial X_{i}}{\partial U_{k}}=0 \Rightarrow \frac{\partial \omega_{i}^{x}}{\partial U_{k}}=-\frac{\omega_{i}^{x}}{2 X_{i}} \frac{\partial X_{i}}{\partial U_{k}}
$$


Differentiating equation (23):

$$
\mu_{i}^{x}-\sum_{j=1}^{N_{c}} v_{i j} \mu_{j}^{c}-\omega_{i}^{x}=0 \Rightarrow \frac{\partial}{\partial U_{k}}\left(\mu_{i}^{x}-\sum_{j=1}^{N_{c}} v_{i j} \mu_{j}^{c}\right)-\frac{1}{R T} \frac{\partial \omega_{i}^{x}}{\partial U_{k}}=0
$$

Substituting the result of (36) into (37):

$$
X_{i} \frac{\partial}{\partial U_{k}}\left(\mu_{i}^{x}-\sum_{j=1}^{N_{c}} v_{i j} \mu_{j}^{c}\right)+\frac{\omega_{i}^{x}}{2 R T} \frac{\partial X_{i}}{\partial U_{k}}=0
$$

It is possible to apply equation (38) in three different ways depending on the type of species considered:

b.1) For aqueous secondary species, where $\omega_{i}^{x}=0$ and $X_{i} \neq 0$, the following expression is obtained:

$$
\frac{\partial}{\partial U_{k}}\left(\mu_{i}^{x}-\sum_{j=1}^{N_{c}} v_{i j} \mu_{j}^{c}\right)=0 \Rightarrow \frac{1}{X_{i}} \frac{\partial X_{i}}{\partial U_{k}}-v_{i 1} \frac{1}{a_{w}} \frac{\partial a_{w}}{\partial U_{k}}-\sum_{j=2}^{N_{c}} v_{i j} \frac{1}{C_{j}} \frac{\partial C_{j}}{\partial U_{k}}=0
$$

where $a_{w}$ is the chemical activity of water (solvent of the liquid phase). In this formulation water is primary species $1\left(a_{w}=a_{1}\right)$. Equation (39) corresponds to the linearized mass action law.

b.2) For pure minerals present in the system where $\omega_{i}^{x}=0$ and $X_{i} \neq 0$, and if, furthermore, its chemical potential $\mu_{i}^{x}$ is constant, the following results:

$$
\frac{\partial}{\partial U_{k}}\left(\mu_{i}^{x}-\sum_{j=1}^{N_{c}} v_{i j} \mu_{j}^{c}\right)=0 \Rightarrow v_{i 1} \frac{1}{a_{w}} \frac{\partial a_{w}}{\partial U_{k}}+\sum_{j=2}^{N_{c}} v_{i j} \frac{1}{C_{j}} \frac{\partial C_{j}}{\partial U_{k}}=0
$$

that corresponds to the linearization of the solubility product.

b.3) For minerals not present in the system, where $\omega_{i}^{x} \neq 0$ and $X_{i}=0$, then:

$$
\frac{\partial X_{i}}{\partial U_{k}}=0
$$

In equations (39) and (40), it was assumed that the chemical activities of the aqueous species $a_{j}$ and $a_{i}$ are given by:

$$
a_{j}=m_{j} \gamma_{j}=\frac{C_{j}}{w_{l}^{w}} \gamma_{j}, \quad a_{i}=m_{i} \gamma_{i}=\frac{X_{i}}{w_{l}^{w}} \gamma_{i}
$$

where $m_{j}$ and $m_{i}$ are the concentrations of the species of the primary and secondary species, respectively expressed in mol/ $/ \mathrm{kg} \mathrm{H}_{2} \mathrm{O}$ and $\gamma_{j}$ and $\gamma_{i}$ 


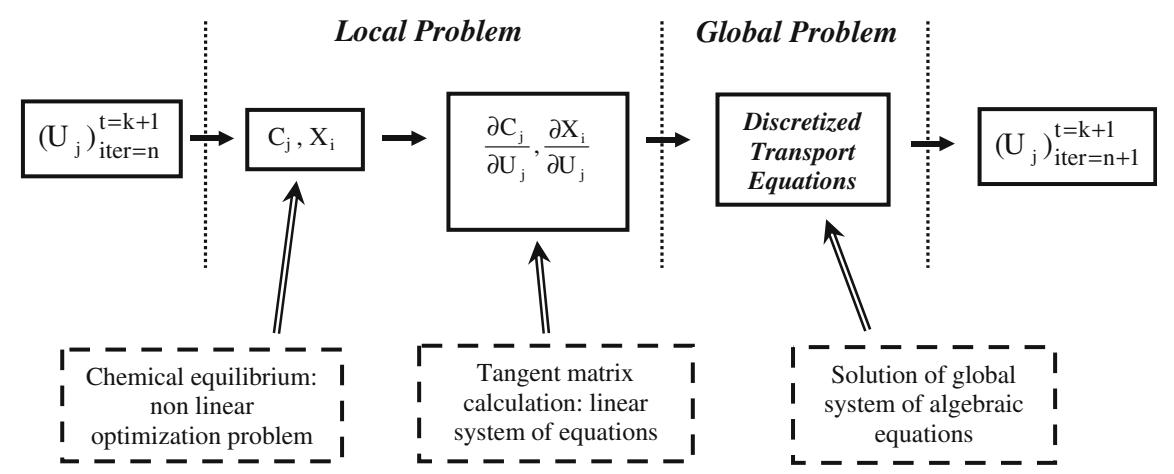

Figure 1. Numerical implementation of the reactive transport problem into a finite element code.

their respective activity coefficients. Concentrations $C_{j}$ and $X_{i}$ are given in $\mathrm{mol} / \mathrm{kg}$ of liquid. For simplicity, in this development the water mass fraction in the liquid $w_{l}^{w}$ and the activity coefficients, $\gamma_{j}$ and $\gamma_{i}$, were assumed constant. Therefore, their derivatives with respect to $U_{k}$ are neglected.

Equations (34) and (39)-(41) define a linear system of equations the unknowns of which are the derivatives of the concentrations of the primary and secondary species with respect to the total analytical concentrations of the primary species, i.e. the components of the tangent matrix (33). This matrix will be used in the solution of the non-linear equations system of the reactive transport problem using the Newton-Raphson method.

In the numerical implementation of the present formulation, the computation of the (non-linear) chemical equilibrium and the calculation of the (linear) tangent matrix are performed locally for every node of the finite element mesh before the global assembly of the system for the whole mesh. Figure 1 shows the scheme for a Newton-Raphson iteration (iter= $n+1)$ for time $t=k+1$ to obtain the global unknowns of the problem, $\left(U_{j}\right)_{\text {iter }=n+1}^{t=k+1}$, from the values of the unknowns of the previous iteration $\left(U_{j}\right)_{\text {iter }=n}^{t=k+1}$. The resulting formulation is able to accommodate the various associations of minerals into a single set of equations allowing an efficient implementation in finite element codes.

\section{Validation Exercise}

\subsection{DESCRIPTION OF THE CASE}

A research programme involving the testing of specimens of bentonite under simultaneous heating and hydration (FEBEX, 1997) has been performed at CIEMAT (Madrid, Spain) as part of the FEBEX project. There is considerable information, obtained independently, on the parameters 


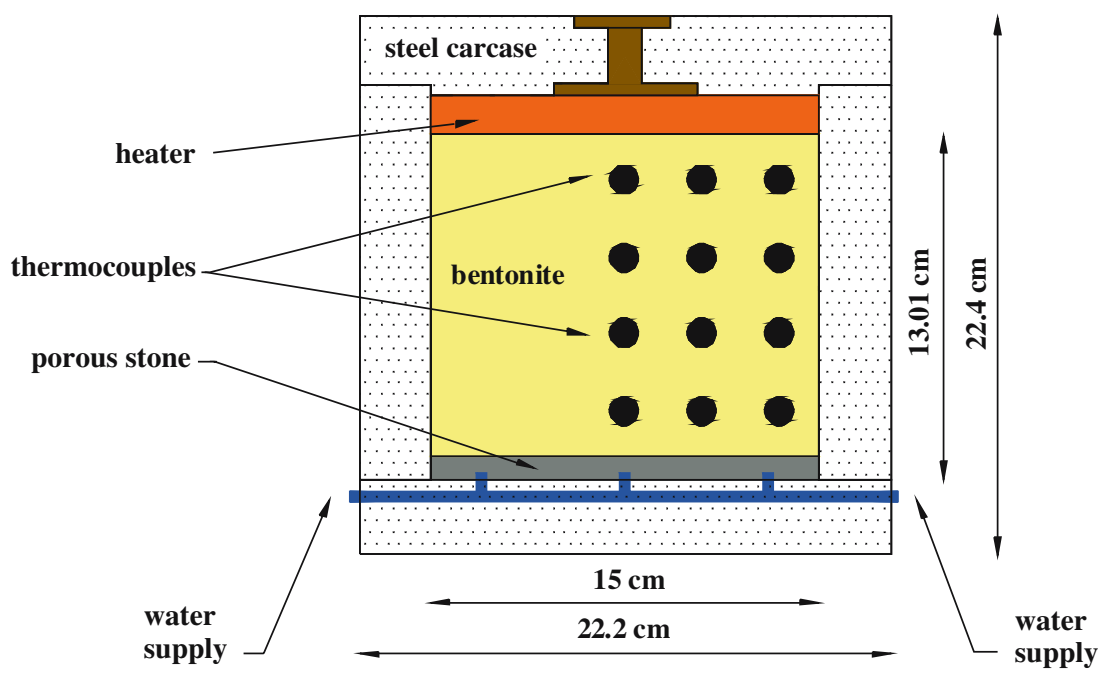

Figure 2. Layout of the test.

required by the modelling. Comprehensive chemical characterization of the clay mineral, interstitial water and hydration water has also been performed (FEBEX, 2000). Temperatures were measured throughout the test. Degree of saturation, porosity and chemical composition of the water were observed in small specimens obtained after dismantling the tests. Those experiments provide, therefore, a useful case for validating the formulation above.

In the test selected for analysis (Cuevas et al., 1996; FEBEX, 1997), a cylindrical sample of swelling clay was compacted one-dimensionally in a rigid steel cell and subjected to heating and hydration from the two opposite sides of the cylinder (Figure 2). The inner dimensions of the cell are: diameter $15 \mathrm{~cm}$ and height $13 \mathrm{~cm}$. Hydration is performed through the lower porous stone under a $1 \mathrm{MPa}$ constant water pressure. On the upper part of the specimen, a heater applies a constant $100^{\circ} \mathrm{C}$ temperature. This boundary temperature was achieved gradually over a period of $5 \mathrm{~h}$. The initial conditions of the bentonite were as follows: dry density $1.62 \mathrm{~g} / \mathrm{cm}^{3}$ and water content $11.2 \%$. This results in an initial porosity of 0.4 and an initial degree of saturation of 0.44 .

Thermocouples installed inside the specimen (Figure 2) measure the evolution of temperatures during the test. Hydration and heating were maintained for 109 days. After cooling, the cell was dismantled and the final distributions of water content, porosity, aqueous concentrations, $\mathrm{pH}$ and adsorbed cation concentrations were measured.

A fully coupled THMC numerical analysis of this experiment has been performed applying the formulation described above. In the modelling, 


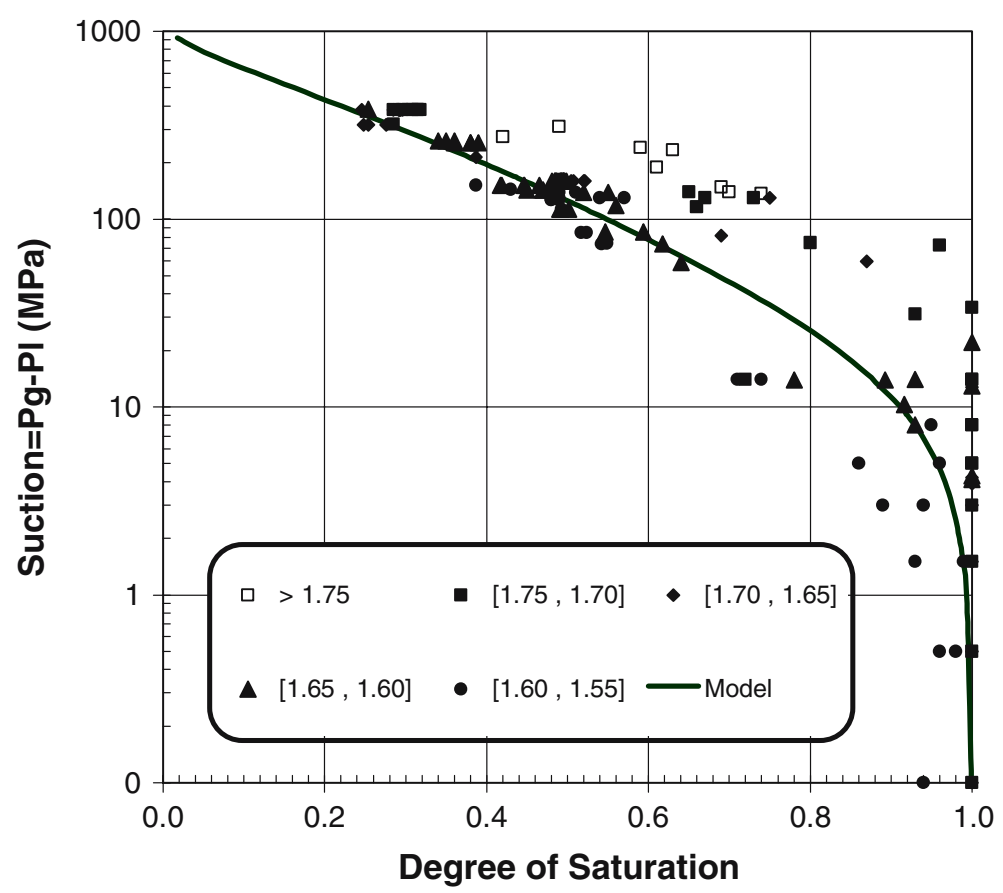

Figure 3. Adopted retention curve compared with experimental results. The different symbols refer to the various dry densities of the specimens tested.

only the bentonite specimen has been considered, represented by a one-dimensional mesh $13 \mathrm{~cm}$ long divided in 50 equal-size elements. This guarantees a Peclet number lower than 2 for transport problems. In the thermal problem, the following heat dissipation boundary condition has been applied:

$$
Q^{*}=h_{0}\left(T-T_{0}\right)
$$

where $Q^{*}$ denotes the lateral heat loss of the bentonite sample.

Although a single coupled THMC analysis has been performed, the THM and reactive transport results are discussed separately in the following sections.

\subsection{THM APPROACH AND RESULTS}

The constitutive relationships required to define the THM behaviour of the bentonite are presented in Gens et al. (1998, 2002). Only the most relevant and modified ones are specifically discussed in this section.

For the retention curve, usually a critical element in THM modelling, a modified form of van Genuchten (1980) expression is used: 


$$
\frac{S_{l}-S_{l r}}{S_{l s}-S_{l r}}=S_{e}=\left[1+\left(\frac{P_{g}-P_{l}}{P_{0} \frac{\sigma}{\sigma_{0}}}\right)^{\frac{1}{1-\lambda}}\right]^{\lambda}\left[1-\frac{P_{g}-P_{l}}{P_{s}}\right]^{\lambda_{s}}, \quad P_{g}-P_{l} \geqslant 0
$$

where $\lambda_{s}, P_{s}$ (in $\mathrm{MPa}$ ), $\lambda, \sigma_{0}$ (in $\mathrm{N} / \mathrm{m}$ ) and $P_{0}$ (in $\mathrm{MPa}$ ) are material parameters. The surface tension $\sigma$ (in $\mathrm{N} / \mathrm{m}$ ) dependency on temperature was obtained based on the values of surface tension given in Custodio and Llamas (1983):

$$
\sigma=0.03059 \exp \left(\frac{252.93}{273.15+T}\right) \mathrm{N} / \mathrm{m}
$$

The modification is required for matching the actual bentonite behaviour at high suction values (FEBEX, 2000). The parameters adopted to define this law have been based on tests carried on samples at different dry densities (Figure 3). They are: $P_{0}=18 \mathrm{MPa}, \sigma_{0}=0.072 \mathrm{~N} / \mathrm{m}, \chi=0.2, \chi_{s}=$ $1.5, P_{s}=1000 \mathrm{MPa}, S_{l r}=0.01$ and $S_{l s}=1$. In the analysis the gas pressure was fixed at $P_{g}=0.1 \mathrm{MPa}$ (atmospheric). Consequently, from the adopted retention curve, an initial liquid pressure of $P_{l}=-165 \mathrm{MPa}$ was obtained corresponding to the initial degree of saturation $S_{1}=0.44$.

Intrinsic permeability controls the rate of progress of hydration. In the analysis an exponential relationship with porosity was used:

$$
\mathbf{k}=k_{0} \exp \left[a\left(\phi-\phi_{0}\right)\right] \mathbf{I}
$$

It was based on the experimental data shown in Figure 4 (FEBEX, 2001). The corresponding parameters are $k_{0}=3.7 \times 10^{-21} \mathrm{~m}^{2}, a=25$ and $\phi_{0}=0.40$. Another parameter concerning the hydraulic problem is the tortuosity for vapour diffusion, estimated as $\tau=0.8$. Indeed the same tortuosity value has been used for the reactive transport equations.

Regarding the thermal problem, the values adopted for the thermal conductivities for the saturated and dry states of the bentonite are $\lambda_{\text {sat }}=$ $1.15 \mathrm{~W} / \mathrm{m} / \mathrm{K}$ and $\lambda_{\text {dry }}=0.47 \mathrm{~W} / \mathrm{m} / \mathrm{K}$ (FEBEX, 2000). So, thermal conductivity of the medium depends on degree of saturation and is given by (Gens et al., 1998, 2002):

$$
\lambda=\lambda_{\text {dry }}\left(1.0-\sqrt{S_{l}}\right)+\lambda_{\text {sat }} \sqrt{S_{l}} \mathrm{~W} / \mathrm{m} / \mathrm{K}
$$

The internal energy of the solid phase (in $\mathrm{J} / \mathrm{kg}$ ) is computed using:

$$
E_{s}=E_{s}^{0} T+\frac{c_{p}}{2} T^{2}
$$

where $E_{s}^{0}=732.5 \mathrm{~J} / \mathrm{kg} /{ }^{\circ} \mathrm{C}$ and $c_{p}=1.38 \mathrm{~J} / \mathrm{kg} /{ }^{\circ} \mathrm{C}^{2}$ (FEBEX, 2000).

Finally, regarding the mechanical constitutive law, a thermo-elastoplastic model for unsaturated soils (Gens, 1995) has been used. It is an 
extension of the Barcelona Basic Model, (BBM) (Alonso et al., 1990) incorporating temperature effects. Parameters were adjusted for the initial dry density of $1.62 \mathrm{~g} / \mathrm{cm}^{3}$ based on the final distribution of porosities of the test. This exercise is not therefore a check on the performance of the mechanical model.

During the performance of the test involved only temperatures were measured. Figure 5 shows the observed and computed distributions of temperatures at various times using $h_{0}=204 \mathrm{~W} / \mathrm{m}^{2} / \mathrm{K}$ and $T_{0}=293.15 \mathrm{~K}$. In fact, temperature reaches equilibrium early on in the test with only minimal changes afterwards.

In Figure 6 the distributions of degree of saturation at various times are presented. Comparison with observations is of course only possible with the observed values at the end of the test. It can be noted that drying has occurred close to the heater whereas the degree of saturation has increased near the hydration end. The changes in porosity presented in Figure 7 are the result of the combined hydration and heating action. The bentonite shrinks near the heater while it undergoes swelling at the opposite end. Overall, the sample volume remains practically constant. Again comparisons are performed with the porosity values obtained at the end of the experiment.

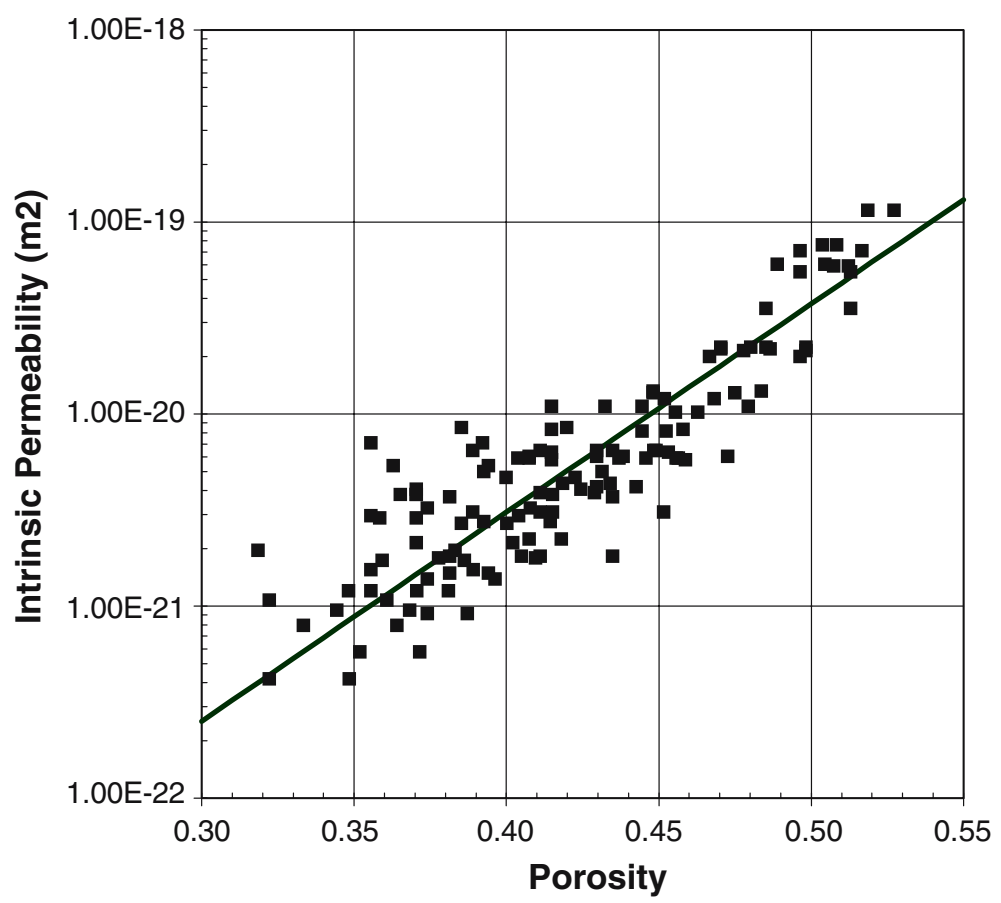

Figure 4. Intrinsic permeability used in the analysis compared with experimental results. 
On the whole, it is probably fair to state that the numerical model is capable of reproducing in a satisfactory manner the observed experimental results of the THM problem.

\subsection{REACTIVE TRANSPORT ANALYSIS}

According to the geochemical characterization studies of the bentonite (FEBEX, 2000), the main processes that take place in the waterbentonite system are dissolution/precipitation of carbonates, sulphates, halite and chalcedony as well as cation exchange. It is also assumed that the geochemical system is in equilibrium with the atmospheric gaseous $\mathrm{CO}_{2}$ at a partial pressure of $10^{-3.5} \mathrm{~atm}$. This hypothesis is difficult to check directly but it has a significant influence on the evolution of the main geochemical variables of the system.

The main exchangeable cations are calcium, magnesium, sodium and potassium (denoted respectively by $\mathrm{CaX}_{2}, \mathrm{MgX}_{2}, \mathrm{NaX}$ and $\mathrm{KX}$, where $\mathrm{X}^{-}$represents the exchange site in the clay mineral. For exchangeable cations, an approximate thermodynamic formulation (Gaines-Thomas) was used based on selectivity coefficients. This formulation allows the inclusion of exchange reactions in the chemical equilibrium problem (Appelo and Postma, 1993). In this simplified formulation, the sum of concentrations of exchangeable cations compensates the excess of negative electrical charge in the clay, represented by the CEC (cation exchange capacity). A clay with large CEC shows large concentrations of exchangeable cations

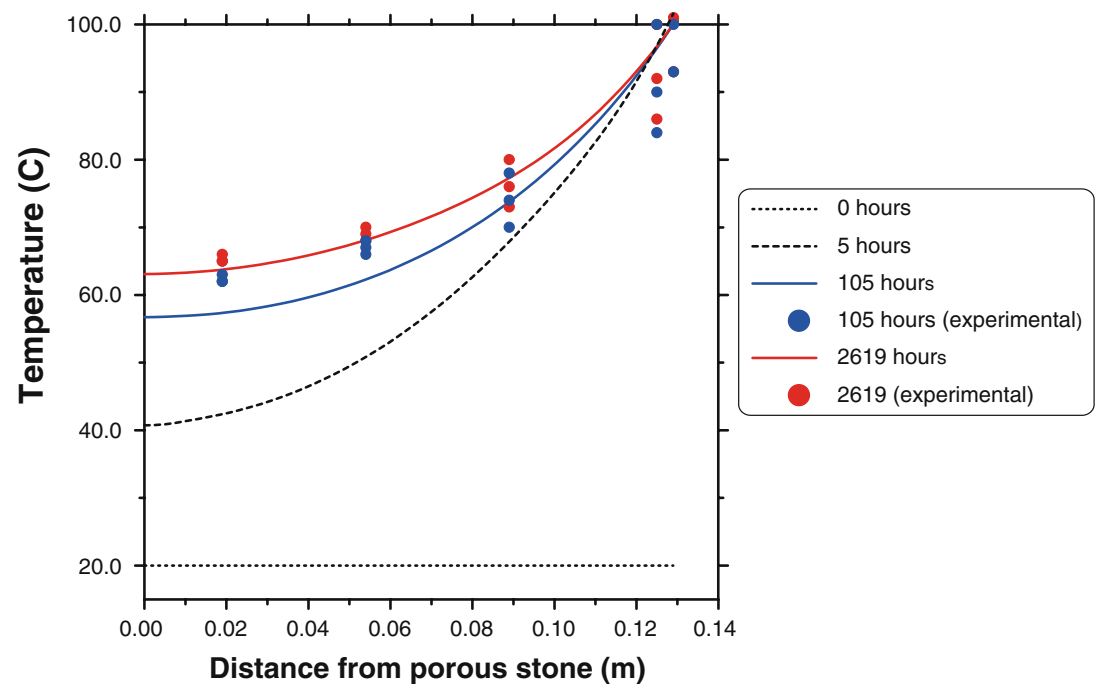

Figure 5. Distributions of temperatures inside the specimen at various times. Computed and observed results. 


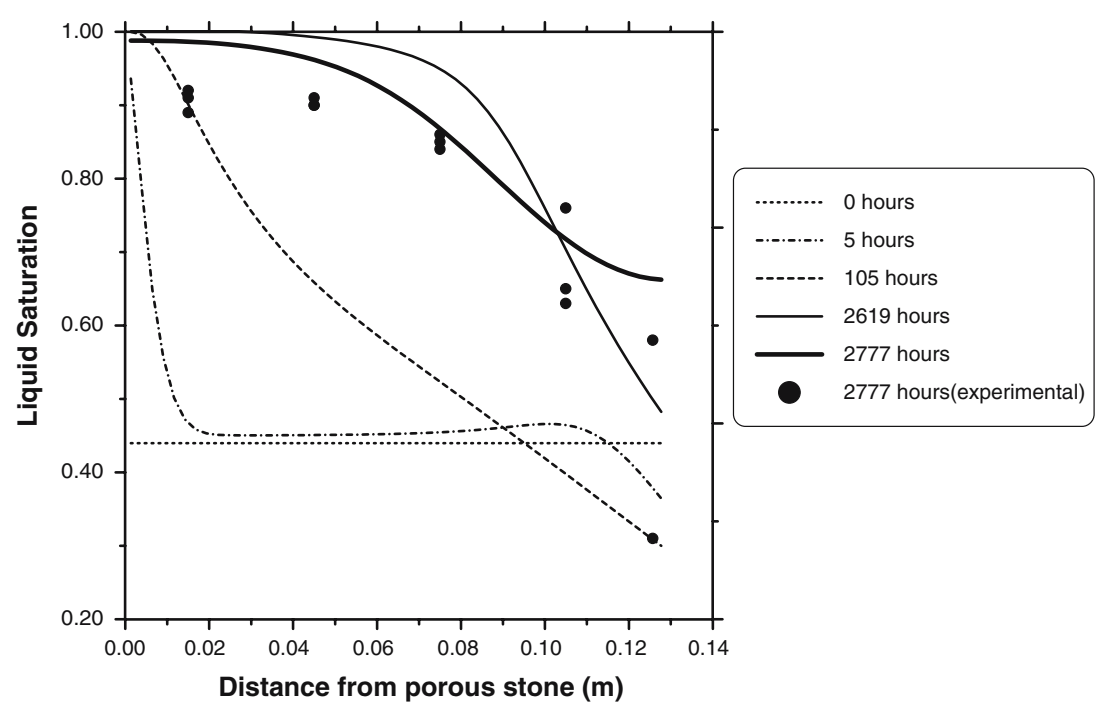

Figure 6. Distribution of degree of saturation inside the specimen at the end of the test. Computed and observed results.

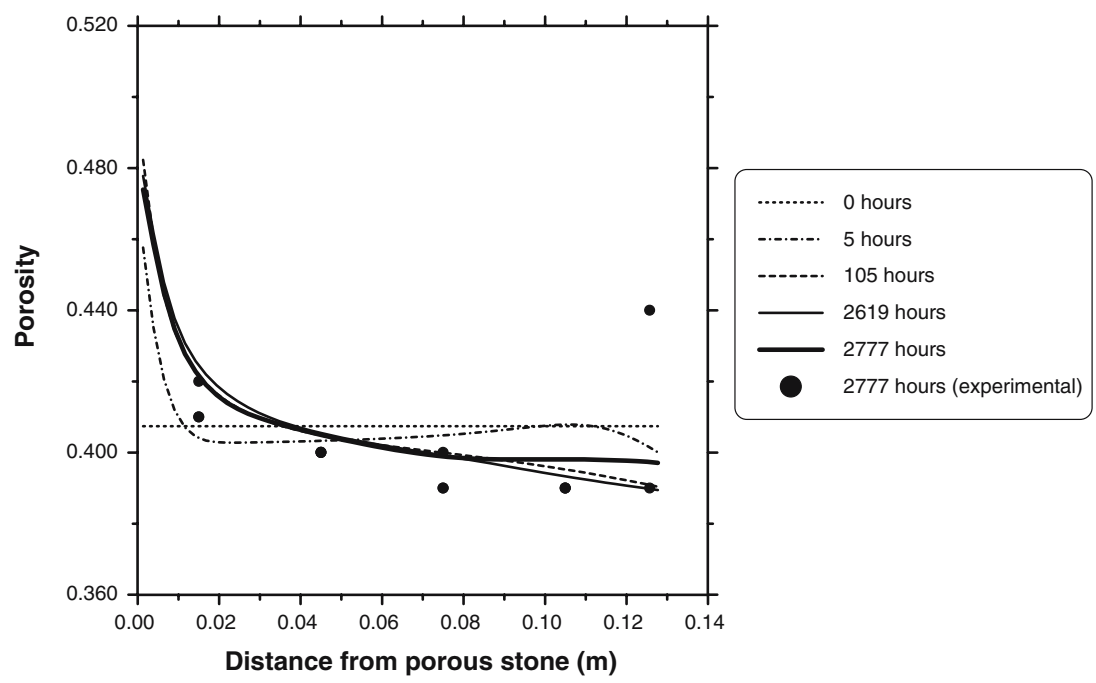

Figure 7. Distribution of porosity inside the specimen at the end of the test. Computed and observed results.

and therefore the charge is not balanced in the pore water (Fernández, 2004; Leroy and Revil, 2004), however the system (clay + pore water is electrically neutral.

Table I shows the initial conditions of the reactive transport problem (FEBEX, 2000). The concentration values in mol $/ \mathrm{kg}$ of liquid represent the 
Table I. Initial conditions for geochemical modelling

\begin{tabular}{lll}
\hline $\begin{array}{l}\text { Dissolved and precipitated } \\
\text { minerals or exchangeable } \\
\text { cations }\end{array}$ & $\begin{array}{l}\text { Percentages of solid (for minerals) } \\
\text { or percentage of } C E C \\
\text { (for exchangeable cations) }\end{array}$ & $\begin{array}{l}\text { mol } / \mathrm{kg} \text { of liquid } \\
\text { (at } 11.2 \% \text { water } \\
\text { content) }\end{array}$ \\
\hline $\mathrm{CaSO}_{4}$ & 0.14 & 0.09178 \\
$\mathrm{NaCl}$ & 0.13 & 0.19841 \\
$\mathrm{CaCO}_{3}$ & 0.6 & 0.53518 \\
$\mathrm{SiO}_{2}$ & 0.038 & 0.056453 \\
$\mathrm{CaX}_{2}$ & 41 & 1.57777 \\
$\mathrm{MgX}$ & 31 & 1.19295 \\
$\mathrm{NaX}$ & 25 & 1.92411 \\
$\mathrm{KX}$ & 3 & 0.23089 \\
\hline
\end{tabular}

initial conditions for a water content of $11.2 \%$. A cation exchange capacity of $C E C=86.2 \mathrm{meq} / 100 \mathrm{~g}$ of solid has been considered (Cuevas et al., 1996).

Table II summarizes the geochemical model adopted (Fernández and Rivas, 1999). All species present in the system are written in terms of the primary species through the corresponding chemical reactions. The B-dot model (Wolery, 1992) was used for the computation of the activity coefficients of the aqueous species in dilute solution and its database for obtaining the equilibrium constants of the chemical reactions. The selectivity coefficients for the Gaines-Thomas convention adopted here are: $K_{\mathrm{Na} \backslash \mathrm{Ca}}=$ $0.293, K_{\mathrm{Na} \backslash \mathrm{K}}=0.115, K_{\mathrm{Na} \backslash \mathrm{Mg}}=0.339(\mathrm{FEBEX}, 2000)$. Those values are consistent with those found in the literature for this type of reactions (Appelo and Postma, 1993).

The initial conditions of the reactive transport problem in terms of total analytical concentration of the primary species are defined from the initial concentrations of Table I and the reactions shown in Table II. For the carbonic gas in equilibrium with the system at $10^{-3.5} \mathrm{~atm}$, an initial free mass of $1 \mathrm{~mol} / \mathrm{kg}$ of liquid is considered so that it is never exhausted. The total analytical concentrations of the primary species are consequently given by

$$
\begin{aligned}
& U_{\mathrm{Ca}}=C_{\mathrm{CaCO}_{3}}+C_{\mathrm{CaSO}_{4}}+C_{\mathrm{CaX}_{2}}=2.20473 \mathrm{~mol} / \mathrm{kg} \\
& U_{\mathrm{K}}=C_{\mathrm{KX}}=0.23089 \mathrm{~mol} / \mathrm{kg} \\
& U_{\mathrm{Na}}=C_{\mathrm{NaCl}}-2 C_{\mathrm{CaX}_{2}}-2 C_{\mathrm{MgX}_{2}}-C_{\mathrm{KX}}=-5.57392 \mathrm{~mol} / \mathrm{kg} \\
& U_{\mathrm{Mg}}=C_{\mathrm{MgX}_{2}}=1.19295 \mathrm{~mol} / \mathrm{kg} \\
& U_{\mathrm{Cl}}=C_{\mathrm{NaCl}}=0.19841 \mathrm{~mol} / \mathrm{kg} \\
& U_{\mathrm{SO}_{4}}=C_{\mathrm{CaSO}_{4}}=0.09178 \mathrm{~mol} / \mathrm{kg}
\end{aligned}
$$


Table II. Geochemical model for the bentonite

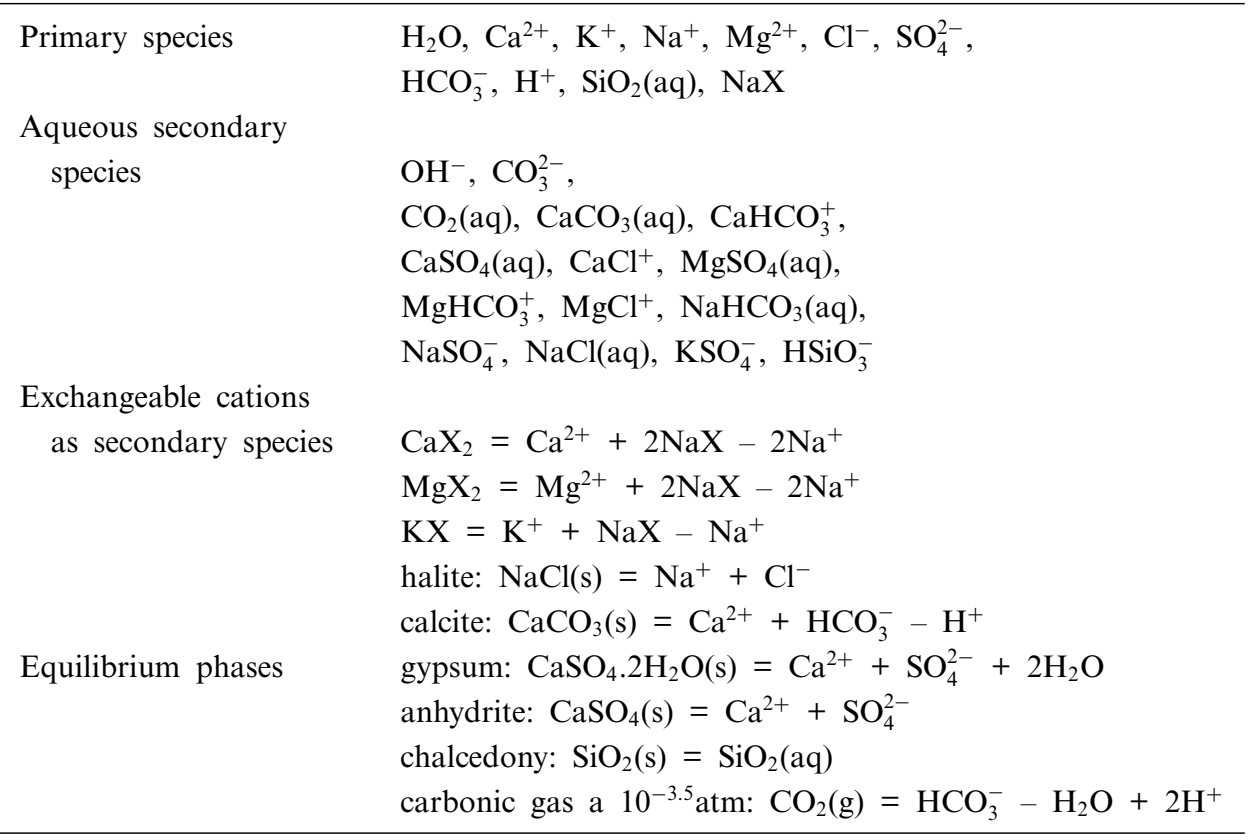

$$
\begin{aligned}
& U_{\mathrm{HCO}_{3}}=C_{\mathrm{CaCO}_{3}}+C_{\mathrm{CO}_{2}(\mathrm{~g})}=1.53518 \mathrm{~mol} / \mathrm{kg} \\
& U_{\mathrm{H}}=-C_{\mathrm{CaCO}_{3}}+C_{\mathrm{CO}_{2}(\mathrm{~g})}=0.46482 \mathrm{~mol} / \mathrm{kg} \\
& U_{\mathrm{SiO}_{2}}=C_{\mathrm{SiO}_{2}}=0.056453 \mathrm{~mol} / \mathrm{kg} \\
& U_{\mathrm{NaX}}=C_{\mathrm{NaX}}+2 C_{\mathrm{CaX}_{2}}+2 C_{\mathrm{MgX}_{2}}+C_{\mathrm{KX}}=7.69644 \mathrm{~mol} / \mathrm{kg}
\end{aligned}
$$

Establishing chemical equilibrium using those values of initial total analytical concentrations at the initial temperature of $20^{\circ} \mathrm{C}$, the chemical composition of the bentonite at a water content of $11.2 \%$ is obtained (Table III). Under those conditions, all halite is dissolved in the liquid phase and will remain so throughout the test. Initially there is no anhydrite either because at $20^{\circ} \mathrm{C}$, gypsum is the more stable sulphate mineral.

Hydration was performed using distilled water, therefore, it is assumed that the water infiltrating into the specimen has a total aqueous concentration equal to zero for all primary species, i.e. it is pure water with a $\mathrm{pH}=7$. This means that one of the main processes occurring in the bentonite will be the dilution of pore water.

The main mechanisms for the dissolved species considered in the modelling are advection and molecular diffusion. It was considered that mechanical dispersion is not significant in solute transport. Advection is more important at the start of the test, when the clay is still very dry and hydration occurs at a high rate. As saturation is approached, molecular 
diffusion becomes more important and for long times, it is the only relevant transport mechanism.

The coefficient of molecular diffusion was adjusted using the distribution of aqueous species in the bentonite obtained at the end of the test from chemical analysis of the water extracted from the pores. Special attention was paid to the $\mathrm{Cl}^{-}$anion, since it is a conservative solute in terms of total aqueous concentration (the halite never precipitates during the test).

Figures 8 and 9 show the agreement achieved regarding the aqueous concentrations of the ions. In the formulation, the hydrodynamic dispersion tensor $\mathbf{D}_{l}$ (equation 4 ) is given by the contributions of molecular diffusion (Fick's law) and mechanical dispersion:

$$
\mathbf{D}_{l}=\phi \rho_{l} \tau S_{l} D_{m}^{\text {solute }} \mathbf{I}+\rho_{l} \mathbf{D}_{l}^{\prime}
$$

where $\mathbf{D}_{l}^{\prime}$ is the mechanical dispersion tensor (Bear, 1972) and the molecular diffusion coefficient used is given by

$$
D_{m}^{\text {solute }}=\left(D_{m}\right)^{o} \exp \left[\frac{-q}{R(273.15+T)}\right]
$$

Table III. Chemical composition of the bentonite (pore water, exchangeable

\begin{tabular}{|c|c|}
\hline Pore water & (Total aqueous concentration in $\mathrm{mol} / \mathrm{kg}$ of liquid) \\
\hline $\mathrm{Ca}^{2+}$ & 0.0271558 \\
\hline $\mathrm{K}^{+}$ & 0.0022669 \\
\hline $\mathrm{Na}^{+}$ & 0.1634601 \\
\hline $\mathrm{Mg}^{2+}$ & 0.0268753 \\
\hline $\mathrm{Cl}^{-}$ & 0.1984100 \\
\hline $\mathrm{SO}_{4}^{2-}$ & 0.0374574 \\
\hline $\mathrm{HCO}_{3}^{-}$ & 0.0004657 \\
\hline $\mathrm{SiO}_{2}$ & 0.0001375 \\
\hline $\mathrm{pH}$ & 7.68 \\
\hline Exchangeable cations & (meq/100 $\mathrm{g}$ of solid) \\
\hline $\mathrm{CaX}_{2}$ & 35.5779 \\
\hline $\mathrm{KX}$ & 2.56057 \\
\hline $\mathrm{NaX}$ & 21.9414 \\
\hline $\mathrm{MgX}_{2}$ & 26.1200 \\
\hline Minerals & (\% of solid) \\
\hline halite & 0 \\
\hline calcite & 0.59955 \\
\hline gypsum & 0.10473 \\
\hline anhydrite & 0 \\
\hline chalcedony & 0.03789 \\
\hline
\end{tabular}
cations and minerals) at the initial $11.2 \%$ water content and $20^{\circ} \mathrm{C}$ 
where parameters in equation (51) are $\left(D_{m}\right)^{\circ}=5 \times 10^{-6} \mathrm{~m}^{2} / \mathrm{s}$ and $\mathrm{q}=24530 \mathrm{~J} / \mathrm{mol}$. In this formulation, $\left(D_{m}\right)^{\circ}$ and $q$ are the same for all aqueous species. The tortuosity $\tau$ for the medium (equation 50) was estimated as $\tau=0.8$ (the same value was used for vapour and aqueous species). In fact the values obtained from the adjustment are consistent with the experimental values determined independently for this material (Martín et al., 2000; FEBEX, 2000).

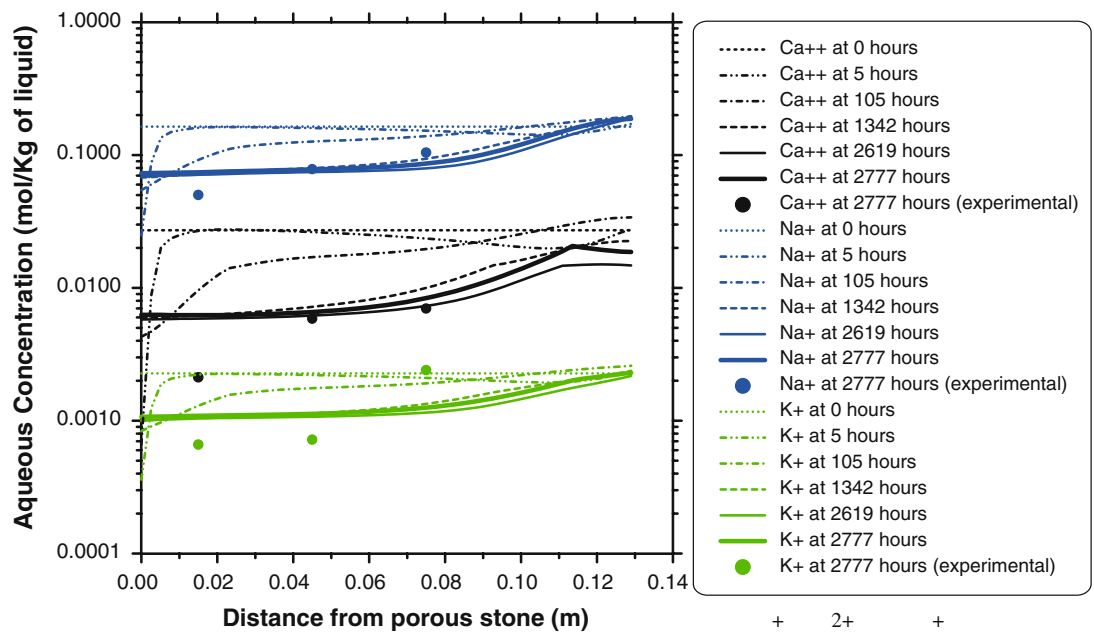

Figure 8. Distribution of the aqueous concentration of cations $\mathrm{Na}^{+}, \mathrm{Ca}^{2+}$ and $\mathrm{K}^{+}$ inside the specimen. Computed results and observed values at the end of the test.

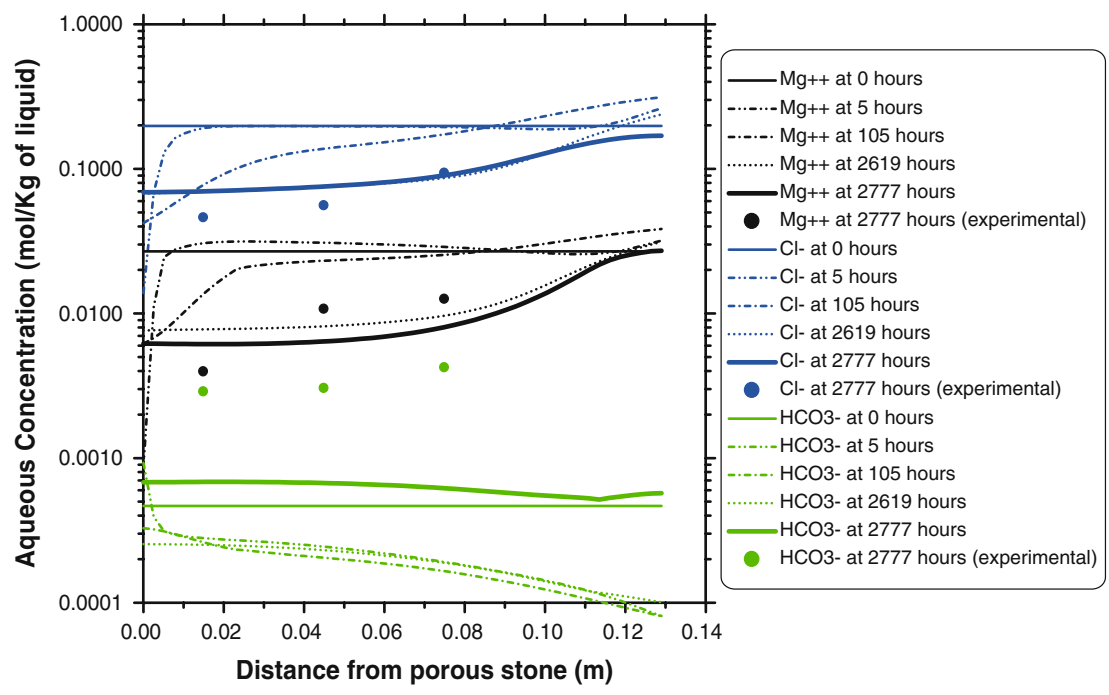

Figure 9. Distribution of the aqueous concentration of ions $\mathrm{Mg}^{2+}, \mathrm{Cl}^{-}$and $\mathrm{HCO}_{3}^{-}$ inside the specimen. Computed results and observed values at the end of the test. 
It can be noted that the concentrations of all aqueous species (except $\mathrm{HCO}_{3}^{-}$) have reduced during the test due to the entrance of distilled water (Figures 8 and 9). The only exception is the $\mathrm{HCO}_{3}^{-}$anion that exhibits a significant increase on cooling. This is due to the solution of calcite at this stage due to its enhanced solubility at lower temperatures. The computed increase is however insufficient to match the observed test results.

Figure 10 shows that the bentonite $\mathrm{pH}$ (both computed and measured values) varies little during the test. The values lie practically always between 7.5 and 8.5, due to the presence of calcite and the assumed equilibrium with carbonic gas. This is an important result because it guarantees the thermodynamic stability of the clay fraction (FEBEX, 2000). A moderate increase of $\mathrm{pH}$ is predicted on cooling due again to the solution of calcite that entails a corresponding consumption of $\mathrm{H}^{+}$, according to

$$
\mathrm{CaCO}_{3}(\mathrm{~s})+\mathrm{H}^{+} \rightarrow \mathrm{Ca}^{2+}+\mathrm{HCO}_{3}^{-}
$$

A parallel increase in $\mathrm{Ca}^{2+}$ is not computed because its concentration is also influenced by cation exchange phenomena.

Regarding the exchangeable cations of the clay (Figure 11), there is also a reasonable correspondence between experimental and computed concentration values except near the heater. The reason for this lack of agreement in the region with temperatures above $70^{\circ} \mathrm{C}$ are unclear at present but they may be due, at least in part, to shortcomings of the cation exchange model at high temperatures. In the model it has been assumed that the equilibrium constants for cation exchange and the CEC do not depend on temperature.

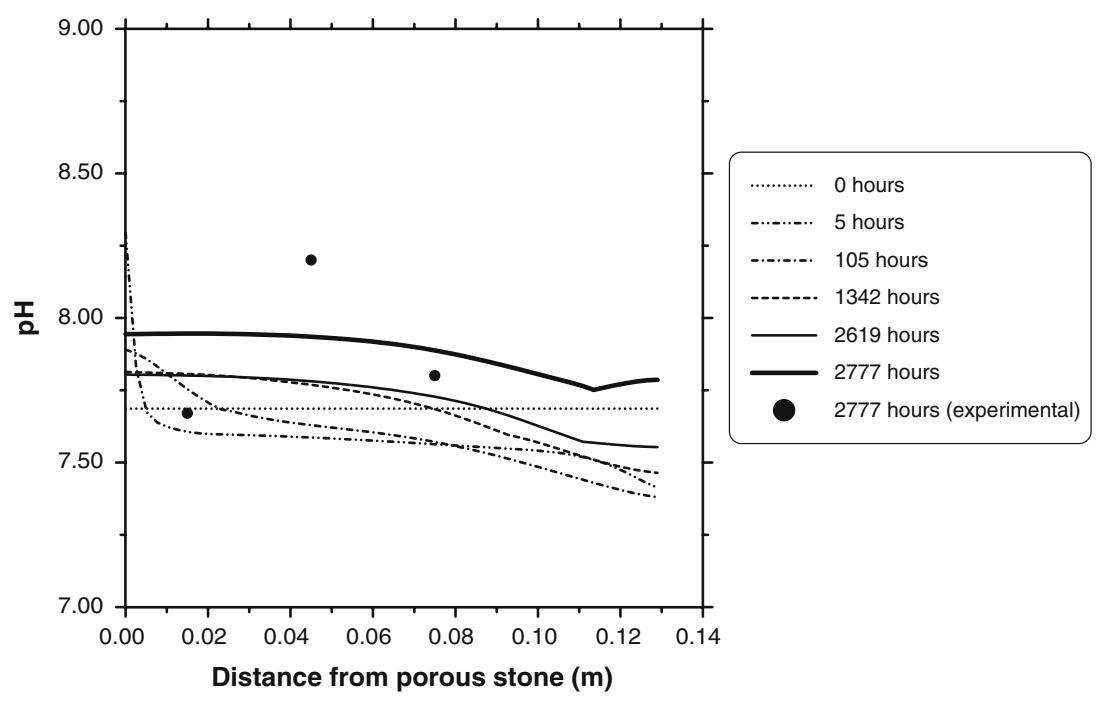

Figure 10. Distribution of $\mathrm{pH}$ inside the specimen. Computed results and observed values at the end of the test. 


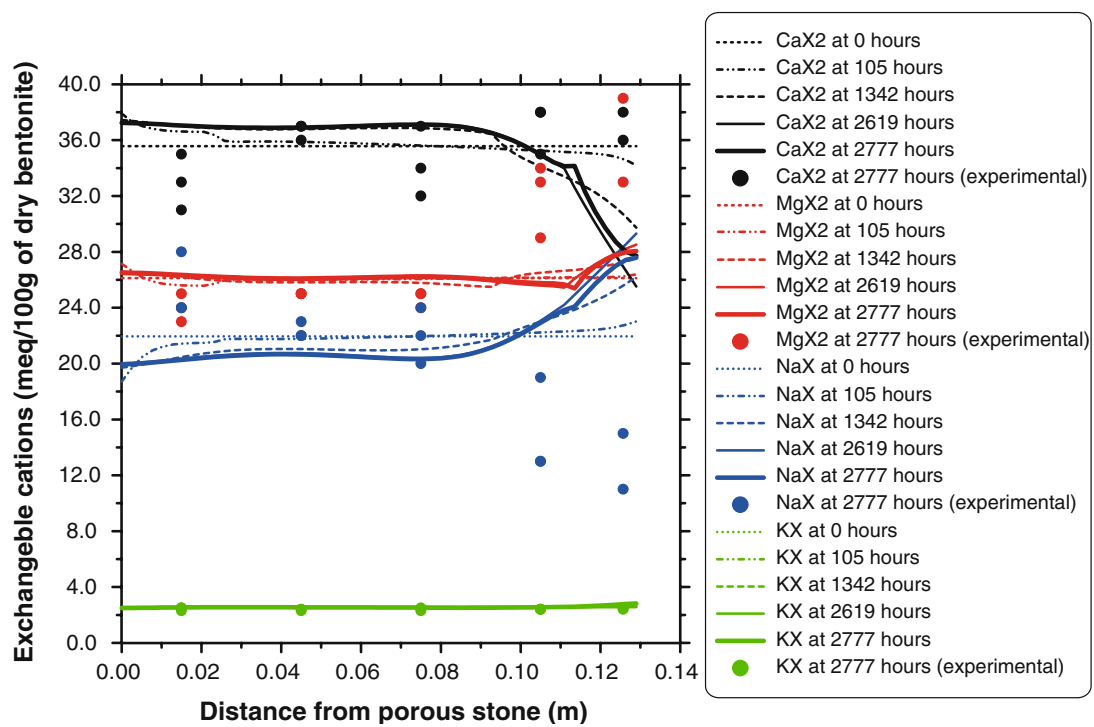

Figure 11. Distribution of the exchangeable cations $\mathrm{CaX}_{2}, \mathrm{MgX}_{2}, \mathrm{NaX}$ and $\mathrm{KX}$ inside the specimen. Computed results and observed values at the end of the test.

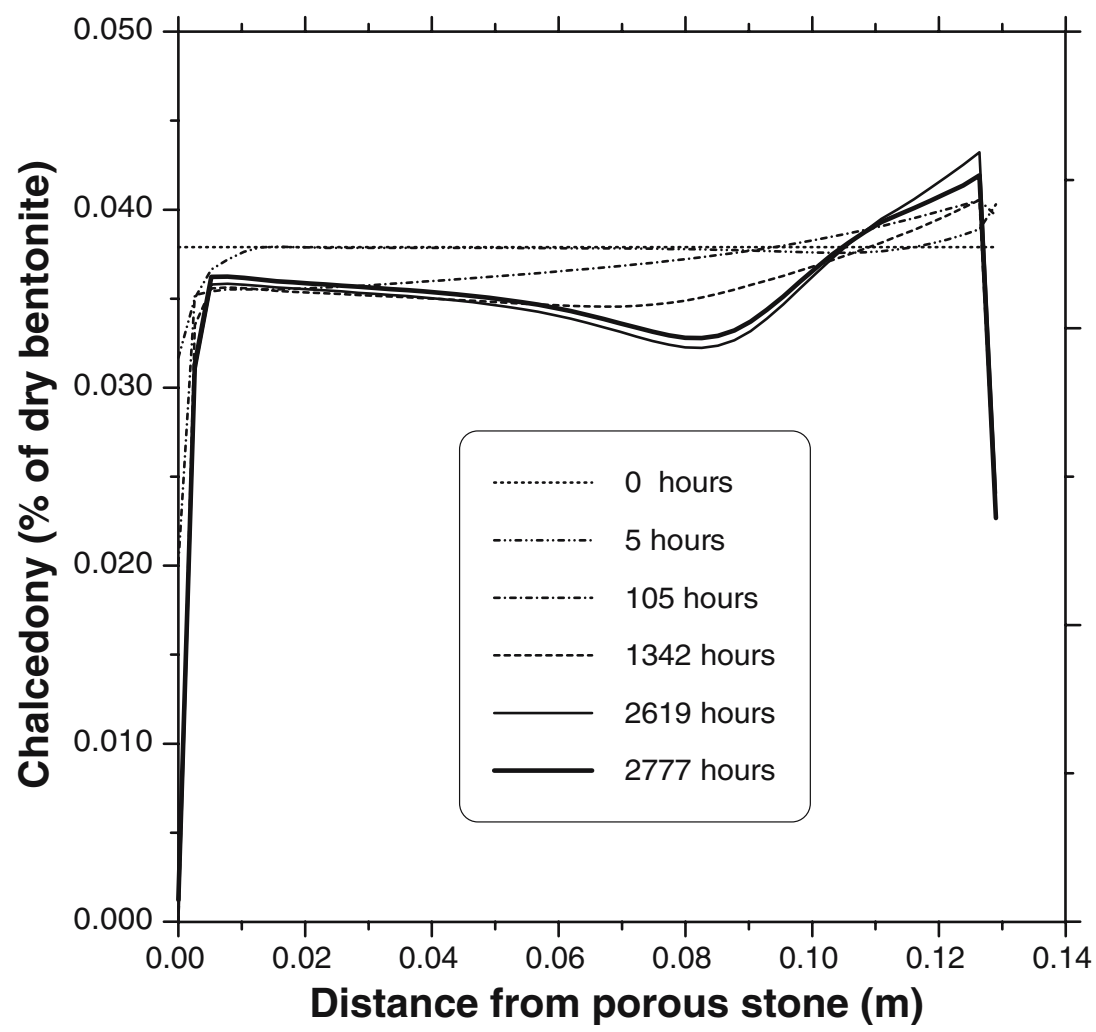

Figure 12. Distributions of chalcedony in the sample. Computed results. 


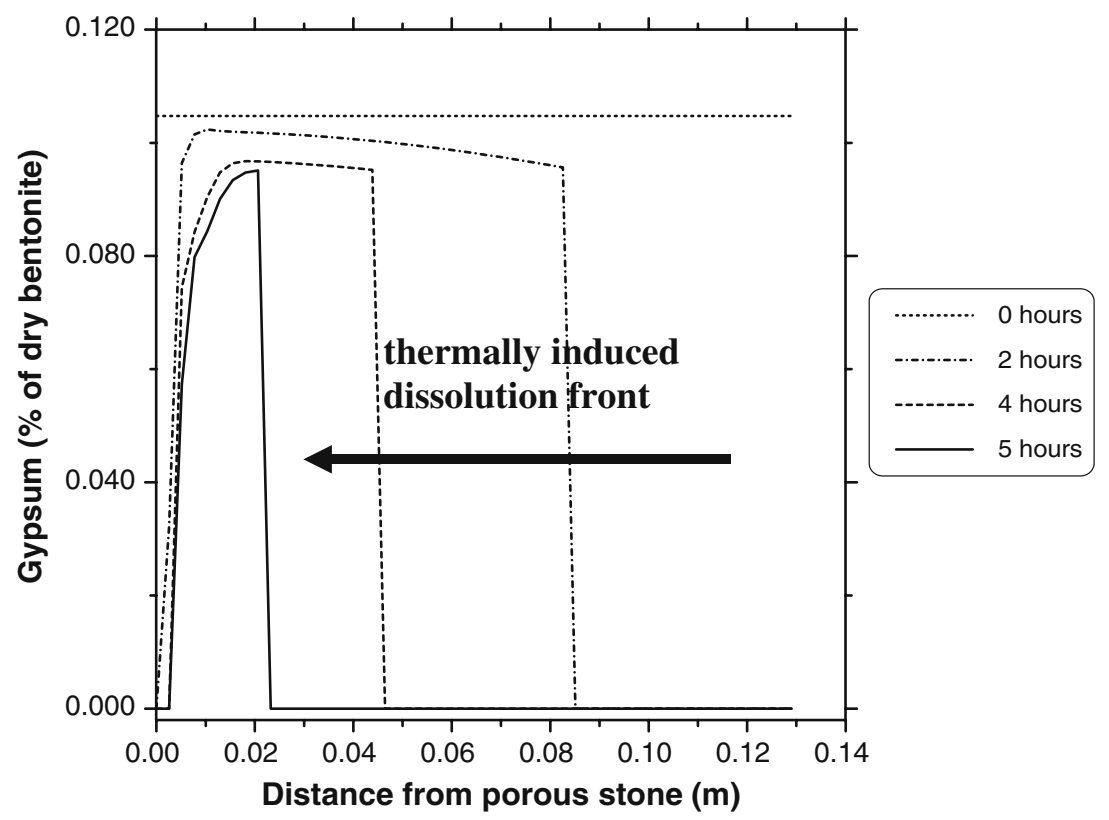

Figure 13. Computed distributions of gypsum in the specimen during the heating phase.

Observing the computed evolution of the other minerals, it can be observed in Figure 12 that, according to the model, chalcedony is dissolved at both ends of the specimen. In the zone close to the porous stone (hydration end) there is a tendency towards the dilution of $\mathrm{SiO}(\mathrm{aq})$ due to hydration with distilled water. In the heater zone, chalcedony exhibits a higher solubility, increasing the concentrations of $\mathrm{SiO}_{2}(\mathrm{aq})$ and generating a flow of this solute by molecular diffusion towards the cooler zones of the sample. This process tends to develop a dissolution front of chalcedony that travels towards the hydration end (colder section) until all chalcedony is dissolved in the hot zone. The limited duration of the test prevents observing the full development of this phenomena.

Sulphates exhibit an evolution somewhat more complex than other minerals. Gypsum is the sulphate mineral more stable at low temperatures, but above $50^{\circ} \mathrm{C}$ gypsum loses water and becomes anhydrite:

$$
\mathrm{CaSO}_{4} \cdot 2 \mathrm{H}_{2} \mathrm{O}(\mathrm{s}) \rightarrow \mathrm{CaSO}_{4}(\mathrm{~s})+2 \mathrm{H}_{2} \mathrm{O}
$$

Equation (53) generates, during the first hours of the test, a gypsum dissolution front and anhydrite precipitation that starts at the heater end and travels towards the cooler sample sections (Figures 13 and 14).

In Figure 15, it is possible to observe the computed evolution of the anhydrite in the sample. The mineral tends to collect near the heater. This 


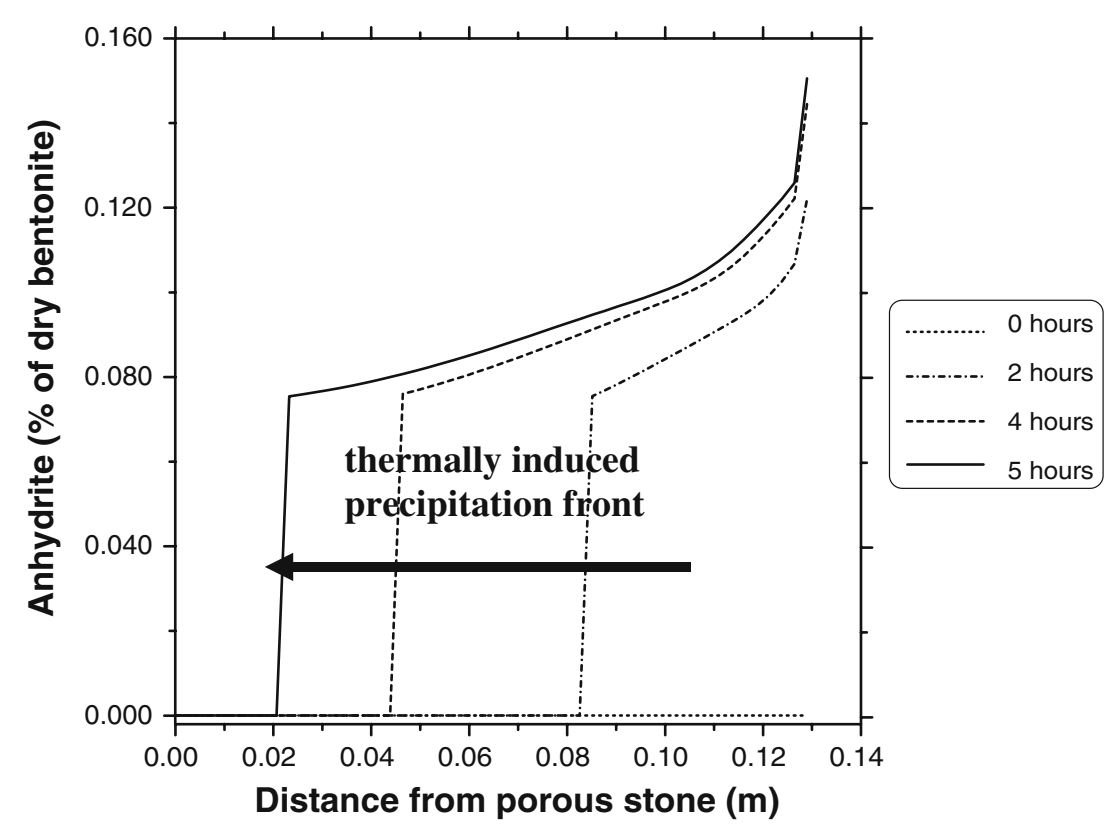

Figure 14. Computed distributions of anhydrite in the specimen during the heating phase.

is a consequence of the evaporation that occurs in that zone. An additional cause lies in the fact that the $\mathrm{Ca}^{2+}$ and $\mathrm{SO}_{4}^{2-}$ ions migrate by molecular diffusion towards the hot zones because the minerals that control their concentrations (calcite, gypsum and anhydrite) are more soluble at low temperatures. Figure 16 shows how the $\mathrm{SO}_{4}^{2-}$ distribution favours the migration by molecular diffusion of this anion towards the heater in the zone where anhydrite is present. This result demonstrates that the formulation is capable of simulating the advance of the dissolution front of the anhydrite towards the hot region including the complete dissolution of the mineral in the cool zone (Figure 15).

In other tests performed by CIEMAT in similar cells, scanning electron microscope observations have shown the existence of a thin film of precipitated gypsum (FEBEX, 1997). Using the optical microscope, accumulation of calcite in zones close to the heater was also noted (FEBEX, 1999). These experimental observations are consistent with the results of the model presented. In the analysis, anhydrite accumulated in the heater becomes gypsum during cooling, following the opposite direction of reaction (53).

\section{Concluding Remarks}

A formulation that generalizes an existing THM code by incorporating the reactive transport equations in an unsaturated deformable porous medium has been presented. The transport and chemical reactions incorporated 


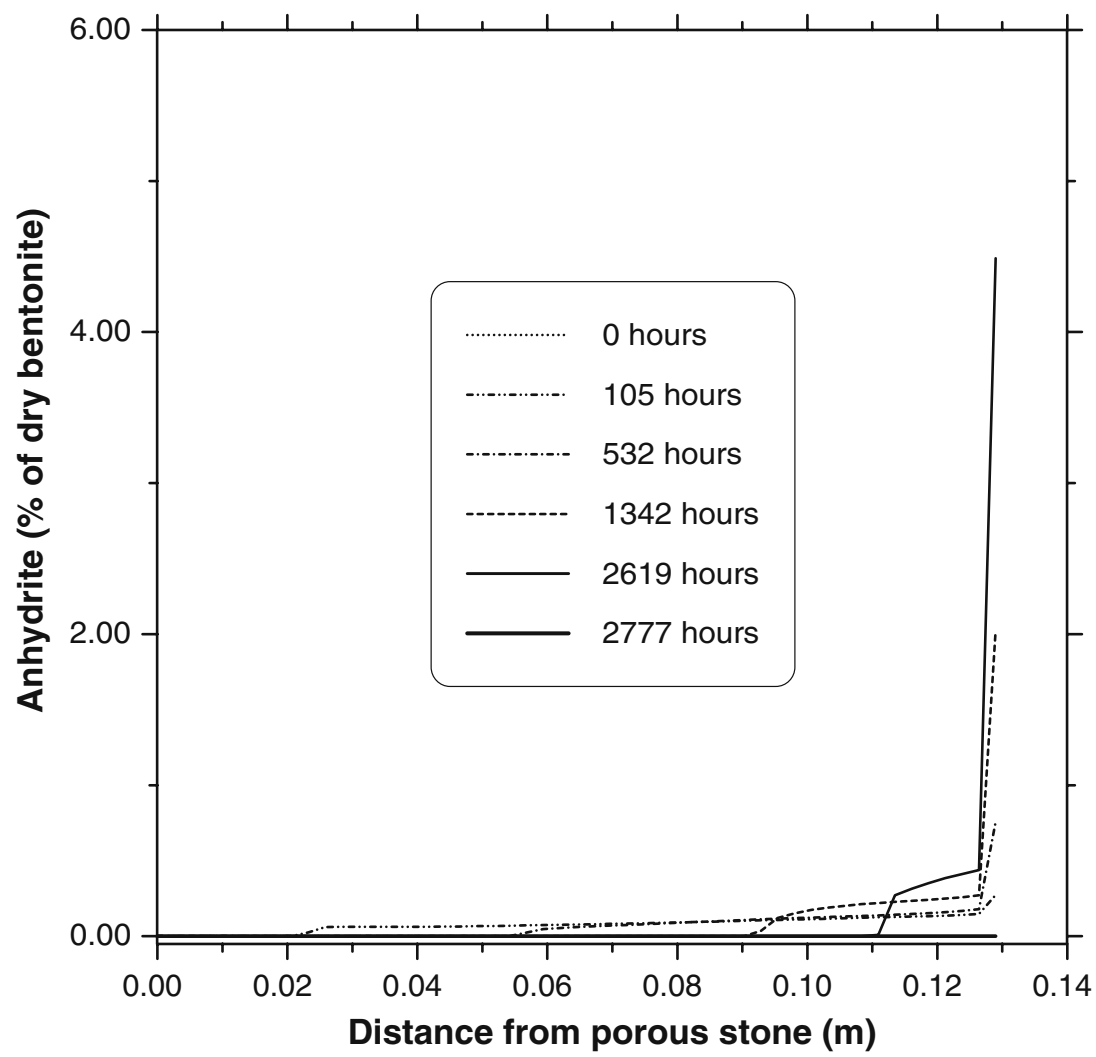

Figure 15. Computed distribution of anhydrite inside the specimen at various times.

are those likely to occur in compacted clay barriers used for isolation of nuclear waste. The formulation is fully coupled allowing, therefore, the examination of the interactions between the various phenomena present in the barrier. The chemical equilibrium equations are solved by ensuring the minimization of Gibbs Free Energy. This approach overcomes the difficulties posed by the possibility of precipitated minerals appearing or disappearing in different parts of the domain. It also allows the use of robust optimization algorithms that contribute significantly to the overall efficiency of the analysis.

A validation exercise involving the simultaneous heating and hydration of a bentonite specimen is described. Encouraging agreement has been found concerning not only THM parameters but chemical variables as well. However, the development of multi-physics models applied to porous media requires more experimental results with simultaneous control of state variables for the thermo-hydro-mechanical and chemical coupled problem. In any case, the numerical tool developed is able to analyze the complex behaviour of clay barriers in a comprehensive manner thereby allowing the 


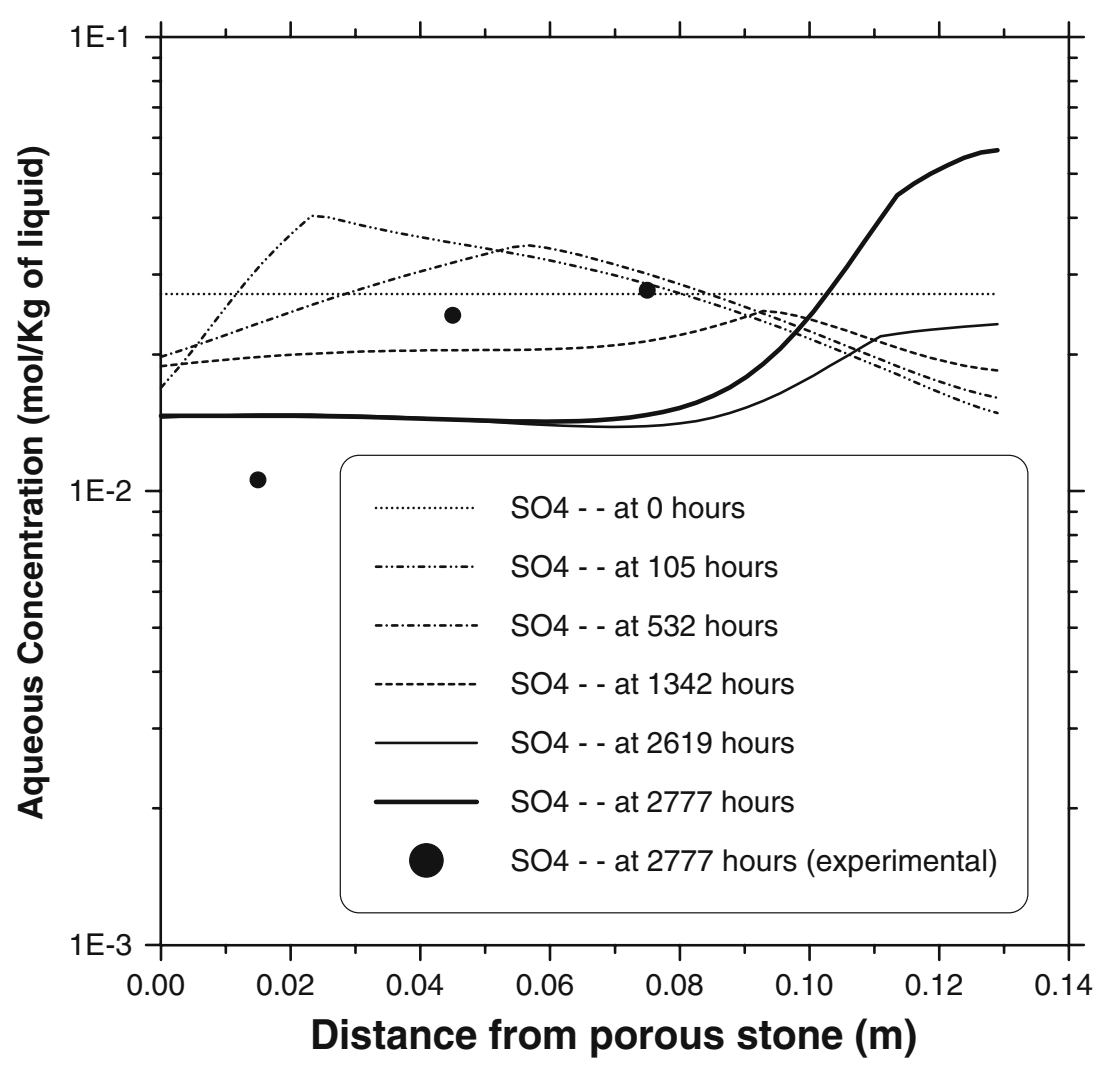

Figure 16. Distribution of the aqueous concentration of $\mathrm{SO}_{4}^{2-}$ inside the specimen. Computed results and observed values at the end of the test.

designer to identify the most significant phenomena to justify subsequent simplifications of the problem for practical applications.

\section{Acknowledegments}

This work has been supported by ENRESA and the European Commision. The authors are also grateful for the financial support given by CAPES (Coordenação de Aperfeiçoamento de Pessoal de Nível Superior, Brazil) and the assistance of the Ministerio de Ciencia y Tecnología of Spain through research grant BTE2001-2227. The Authors also thank CIEMAT for useful discussions and for providing information on the geochemical test.

\section{References}

Alonso, E. E., Gens, A. and Josa, A.: 1990, A constitutive model for partially saturated soils, Géotechnique 40, 405-430.

Anderson, G. and Crerar, D.: 1993, Thermodynamics in Geochemistry - The Equilibrium Model. Oxford University Press, New York, 588 pp. 
Appelo, C. and Postma, D.: 1993, Geochemistry Groundwater and Pollution. Balkema, Rotterdam, 536 pp.

Bear, J.: 1972, Dynamics of Fluids in Porous Media. Dover, 164 pp.

Bethke, C. M.: 1996, Geochemical Reaction Modeling. Oxford University Press, 397 pp. ISBN 0-19-509475-1.

Cheng, H. and Yeh, G.: 1998, Development and demonstrative application of a 3-D numerical model of subsurface, flow, heat transfer, and reactive chemical transport: 3DHYDROGEOCHEM, J. Contam. Hydrol., 34, 47-83.

Cuevas, J., Villar, M. V., Fernández, A. M., Gómez, P. and Martín, P. L.: 1996, Pore waters extracted from compacted bentonite subjected to simultaneous heating and hydration, Appl. Geochem., 12, 473-481.

Custodio, E. and Llamas, M. R.: 1983, Hidrogeología Subterránea, Ed. Omega, Barcelona, ISBN 84-282-0446-2, 2 volúmenes.

FEBEX, 1997, Caracterización geoquímica de bentonita compactada: efectos producidos por flujo termohidráulico. Report 70-IMA-M-0-2. CIEMAT. Madrid, Spain.

FEBEX, 1999, Termo-Hydro-Geochemical Tests on Small Cells. Report 70-IMA-M-0-5. CIEMAT/UAM. Madrid, Spain.

FEBEX, 2000, Full-scale engineered barriers experiment for a deep geological repository for high level radioactive waste in crystalline host rock. Final Report. Publicación técnica 1/2000 de la Empresa Nacional de Residuos Radiactivos (ENRESA). Spain.

FEBEX, 2001, FEBEX II. Informe sobre los resultados de la modelización THM. Informe 70-UPC-L-5-010. UPC-DIT. Barcelona, Spain.

Fernández, A. M.: 2004. Caracterización y Modelización del agua intersticial de materiales arcillosos: Estudio de la bentonita de Cortijo de Archidona. Ph.D. Thesis. Universidad Autónoma de Madrid, Spain, 505 pp. Editorial CIEMAT.

Fernández, A. M. and Rivas, P.: 1999, Personal communication.

Friedly, J. C. and Rubin, J.: 1992, Solute transport with multiple equilibrium-controlled or kinetically-controlled chemical reactions, Water Resour. Res. 28, 1935-1953.

Gawin, D., Baggio, P. and Schrefler, B. A.: 1995, Coupled heat, water and gas flow in deformable porous media. Int. J. Num. Meth. Fluids 20, 967-987.

Gens, A.: 1995, Constitutive Laws, in: A. Gens, P. Jouanna and B. A. Schrefler (eds.), Modern Issues in Non-saturated Soils. Springer-Verlag, pp. 129-158.

Gens, A., García-Molina, A., Alonso, E. E. and Huertas, F.: 1998, Analysis of a full-scale in situ test simulating repository conditions. Int. J. Numer. Anal. Methods Geomech. 22, $515-548$.

Gens, A., Guimarães L. do N., García-Molina, A. and Alonso, E. E.: 2002, Factors controlling rock-clay buffer interaction in a radioactive waste repository. Eng. Geol. 64, 297-308.

van Genuchten, R.: 1980, A closed-form equation for predicting the hydraulic conductivity of unsaturated soils. Soil Sci. Soc. Am. J. 892-898.

Greenberg, P. and M $\phi 1 l e r, ~ N .: ~ 1989$, The prediction of mineral solubilities in natural waters: the Na-K-Ca-Cl- $\mathrm{SO}_{4}-\mathrm{H}_{2} \mathrm{O}$ system to high concentration from 0 to $250{ }^{\circ} \mathrm{C}$. Geochimica et Cosmochimica Acta 53, 2503-2518.

Harvie, C., Greenberg, J. and Weare, J.: 1987, A chemical equilibrium algorithm for highly non-ideal multiphase systems: free energy minimization. Geochimica et Cosmochimica Acta 51, 1045-1057.

Kirkner, D. and Reeves, H.: 1988, Multicomponent mass transport with homogeneous and heterogeneous chemical reactions: effect of the chemistry on the choice of numerical algorithm 1. Theory, Water Resour. Res. 24, 1719-1729.

Leroy, P. and Revil, A.: 2004, A triple-layer model of the surface electrochemical properties of clay minerals, J. Colloid Interface Sci. 270, 371-380. 
Lichtner, P.: 1985, Continuum model for simultaneous chemical reactions and mass transport in hydrothermal systems, Geochimica et Cosmochimica Acta 49, 779-800.

Martín, M., Cuevas, J. and Leguey, S.: 2000, Difusión of soluble saltas under a temperature gradient after the hydration of compacted bentonite. Appl. Clay Sci. 17, 55-70.

Olivella, S., Carrera, J., Gens, A. and Alonso, E. E.: 1994, Nonisothermal multiphase flow of brine and gas through saline media, Transport Porous Media 15, 271-293.

Olivella, S.: 1995, Nonisothermal Multiphase Flow of Brine and Gas Through Saline Media. PhD thesis. Departamento de Ingeniería del Terreno, Universidad Politécnica de Cataluña, Barcelona, España.

Olivella, S., Gens, A., Carrera, J. and Alonso, E. E.: 1996, Numerical formulation for a simulator (CODE_BRIGHT) for the coupled analysis of saline media. Eng. Comput. 13, 87-112.

Reed, M.: 1982, Calculation of multicomponent chemical equilibria and reaction processes in systems involving minerals, gases and an aqueous phase. Geochimica et Cosmochimica Acta 46, 513-528.

Rubin, J.: 1983, Transport of reacting solutes in porous media: Relation between mathematical nature of problem formulation and chemical nature of reactions. Water Resour. Res. 19, 1231-1252.

Saaltink, M., Ayora, C. and Carrera, J.: 1998, A mathematical formulation for reactive transport that eliminates mineral concentrations. Water Resour. Res. 34, 1649-1656.

Schrefler, B. A.: 1995, F. E. in environmental engineering: coupled thermo-hydro-mechanical processes in porous media including pollutant transport. 7th European Autumn School: Non linear modelling of geomaterials with the finite element method. Aussois, France.

Steefel, C. and Lasaga, A.: 1994, A coupled model for transport of multiple chemical species and kinetic precipitation/dissolution reactions with application to reactive flow in single phase hydrothermal systems. Am. J. Sci. 294, 529-592.

Steefel, C. and McQuarrie, K.: 1996, Approaches to modelling of reactive transport in porous media. Rev. Mineral. 34, 83-129.

Thomas, H. R. and He, Y.: 1995, An analysis of coupled heat, moisture and air transfer in a deformable unsaturated soil, Géotechnique, 45, 667-689.

Thomas, H. R., Cleall, P. J. and Hashm, A. A.: 2001, Thermal/hydraulic/chemical/mechanical (THCM) behaviour of partly saturated soil, in: Desai et al. (eds.), Computer Methods and Advances on Geomechanics, Rotterdam: Balkema, 1: pp. 743-748.

White, T.: 1995, Multiphase nonisothermal transport of systems of reacting chemicals. Water Resour. Res. 31, 1761-1772.

Wolery, T. J.: 1992, EQ3NR, A Computer Program for Geochemical Aqueous Speciation-Solubility Calculations: Theoretical Manual, User's Guide, and Related Documentation (Version 7.0). Publicación UCRL-MA-1010662 PT III de Lawrence Livermore National Laboratory (LLNL). USA.

Xu, T., Samper, J., Ayora, C., Manzano, M. and Custodio, E.: 1999, Modeling of nonisothermal multi-component reactive transport in field scale porous media flow systems. J. Hydrol. 214, 144-164.

Yeh, G. and Tripathi, V.: 1991, A model for simulating transport of reactive multispecies components: model development and demonstration. Water Resour. Res. 27, 3075-3094. 